\title{
The Role of Nitric Oxide in Nitrogen Fixation by Legumes
}

\author{
Santiago Signorelli1 ${ }^{1,3 *}$, Martha Sainz' ${ }^{1}$ Sofía Tabares-da Rosa ${ }^{1}$ and Jorge Monza ${ }^{1}$ \\ 1 Laboratorio de Bioquímica, Departamento de Biología Vegetal, Facultad de Agronomía, Universidad de la República, \\ Montevideo, Uruguay, ${ }^{2}$ The School of Molecular Sciences, Faculty of Science, The University of Western Australia, Crawley, \\ WA, Australia, ${ }^{3}$ Australian Research Council Centre of Excellence in Plant Energy Biology, University of Western Australia, \\ Crawley, WA, Australia
}

\section{OPEN ACCESS}

Edited by: Juan B. Barroso, University of Jaén, Spain

Reviewed by: Alexandre Boscari, INRA Centre Provence-Alpes-Côte d'Azur, France Oswaldo Valdes-Lopez, National Autonomous University of Mexico, Mexico

*Correspondence:

Santiago Signorelli ssignorelli@fagro.edu.uy

Specialty section: This article was submitted to Plant Microbe Interactions, a section of the journal Frontiers in Plant Science

Received: 01 December 2019 Accepted: 06 April 2020

Published: 03 June 2020

Citation:

Signorelli S, Sainz M, Tabares-da Rosa S and Monza J (2020) The Role of Nitric Oxide in Nitrogen Fixation by Legumes. Front. Plant Sci. 11:521. doi: 10.3389/fp/s.2020.00521
The legume-rhizobia symbiosis is an important process in agriculture because it allows the biological nitrogen fixation (BNF) which contributes to increasing the levels of nitrogen in the soil. Nitric oxide (.NO) is a small free radical molecule having diverse signaling roles in plants. Here we present and discuss evidence showing the role of .NO during different stages of the legume-rhizobia interaction such as recognition, infection, nodule development, and nodule senescence. Although the mechanisms by which .NO modulates this interaction are not fully understood, we discuss potential mechanisms including its interaction with cytokinin, auxin, and abscisic acid signaling pathways. In matures nodules, a more active metabolism of . $\mathrm{NO}$ has been reported and both the plant and rhizobia participate in . $\mathrm{NO}$ production and scavenging. Although . NO has been shown to induce the expression of genes coding for NITROGENASE, controlling the levels of .NO in mature nodules seems to be crucial as . NO was shown to be a potent inhibitor of NITROGENASE activity, to induce nodule senescence, and reduce nitrogen assimilation. In this sense, LEGHEMOGLOBINS (Lbs) were shown to play an important role in the scavenging of . $\mathrm{NO}$ and reactive nitrogen species (RNS), potentially more relevant in senescent nodules. Even though .NO can reduce NITROGENASE activity, most reports have linked .NO to positive effects on BNF. This can relate mainly to the regulation of the spatiotemporal distribution of . NO which favors some effects over others. Another plausible explanation for this observation is that the negative effect of .NO requires its direct interaction with NITROGENASE, whereas the positive effect of . $\mathrm{NO}$ is related to its signaling function, which results in an amplifier effect. In the near future, it would be interesting to explore the role of environmental stress-induced .NO in BNF.

Keywords: $\cdot$ NO, reactive oxygen species, leghemoglobin, legumes, nitrogen fixation, reactive nitrogen species

\section{INTRODUCTION}

The biological nitrogen fixation $(\mathrm{BNF})$ is the process of reducing atmospheric nitrogen $\left(\mathrm{N}_{2}\right)$ to ammonium $\left(\mathrm{NH}_{4}{ }^{+}\right)$catalyzed by the NITROGENASE enzyme. This process is carried out by a small group of bacteria, in either free-living condition, associated with different plants such as epiphytes or endophytes, or establishing endocellular symbiosis with legumes (Masson-Boivin et al., 2009). The rhizobium-legume symbiosis involves the exchange of carbon source produced 
by the plant and ammonium fixed by the bacteria in specialized organs denominated nodules. This symbiosis helps legumes to naturally colonize nitrogen-poor soils. Thus, this symbiosis positively impacts on agriculture, not only for the savings of nitrogen $(\mathrm{N})$ fertilizers but also due to the reduction of its negative impact on the environment, which is key to achieve sustainable agriculture. Particularly because of the importance of sustainable agriculture, the interest in the BNF has been revitalized in recent years (Sulieman and Tran, 2015), with an emphasis in the rhizobium-legume symbiosis involving the cultivation of food and fodder (Lindström et al., 2010; Laranjo et al., 2014). Moreover, researchers have done considerable efforts to introduce the ability to perform BNF into non-leguminous plants, either by introducing the NITROGENASE enzyme into plants through genetic engineering (Oldroyd and Dixon, 2014) or by using Gluconacetobacter diazotrophicus, a non-nodulating endophytic nitrogen-fixing bacterium (Cocking et al., 2006).

Nitric oxide $(\cdot \mathrm{NO})$ is a small free radical molecule, which is ubiquitous in plants and its production is often enhanced under stress conditions (Corpas et al., 2008, 2011; Signorelli et al., 2013, 2019). ·NO acts as a signaling molecule interacting with hormone signaling in plants (Klessig et al., 2000; Wang et al., 2015a) and regulating different developmental processes such as germination, root elongation, floral transitions, branching, and ripening (Lozano-Juste and Leon, 2011; Sanz et al., 2014; Chaki et al., 2015). The BNF is also modulated by $\cdot \mathrm{NO}$ at different stages of this process. In this review, we present and discuss the metabolism of $\cdot \mathrm{NO}$ in nodules, the different sources of $\cdot \mathrm{NO}$, and its effect on nodule establishment, BNF and nodule senescence. With this, we attempt to provide clear views on what is currently know and highlight the outstanding questions that need to be investigated in this exciting research area.

\section{-NO IN LEGUME-BACTERIA INTERACTION}

The establishment of the legume-rhizobium symbiosis requires the recognition between the rhizobia and legume and the formation of nodules, the plant organ hosting the rhizobia and where the BNF takes place. The nodule provides a low oxygen (microoxic) environment which is necessary to prevent the inhibition of the NITROGENASE activity by oxygen $\left(\mathrm{O}_{2}\right)$. To cope with the lower $\mathrm{O}_{2}$ availability, the cytochrome-pathway of respiration of mitochondria from nodules has a higher apparent affinity for $\mathrm{O}_{2}$ than the equivalent of mitochondria from roots (Millar et al., 1995). This allows the nodule cells to produce ATP by oxidative phosphorylation which is used for the rhizobia as the energy source, together with other carbon sources, to fixate nitrogen. The fixated nitrogen is assimilated mostly in the cytosol of the nodule cells and taken up by the plant.

Two genetic pathways were shown to control the number of nodules produced in the root nodule symbiosis, one of them controlling the rhizobial infection and the other one controlling the nodule organogenesis (Penmetsa et al., 2003). Depending on the legume, the nodule can be indeterminate or determinate, which means respectively that they sustain or not meristematic activity (Hirsch, 1992). The nodulation process starts with the release of chemical signals by the root hairs, which attract rhizobia and trigger them to produce bacterial nodulation factors (Nod-factors) (Figure 1 i). These Nod factors are perceived by the legume to promote root cell division and other downstream responses (Geurts and Bisseling, 2002). The rhizobia grow, induce a curl in the root hair (Figure 1 ii) and a tubular and intracellular structure containing the bacteria, known as infection thread, is formed (Figure 1 iii). As the rhizobia reproduce, the infection thread grows reaching first the base of root hair cell and later the nodule primordium (Geurts and Bisseling, 2002). The formation of this infection threat it also induced by the presence of the plant hormones cytokinin (CK) and auxin (AUX) (Roy et al., 2020). Afterward, the infection thread starts to release bacterial cells into the parenchyma cells of the developing nodule, where the bacterial cells differentiate into bacteroids, a transformation that requires morphological and physiological changes (Figure 1 iv). For a detailed review of the nodule formation process, we recommend revising Gage (2004) or Roy et al. (2020).

In the different stages of the nodule formation, a crosstalk between the bacteria and the root cells occurs. Reactive oxygen species (ROS) are present among the molecules involved in this communication. ROS are produced at a high level in the nodule, mainly due to the high demand of respiration to support NITROGENASE activity and the autoxidation of oxygenated leghemoglobin (oxy-Lb) (Puppo et al., 1981). Therefore, the role of ROS on modulating the legume-rhizobia interaction, as well as the relevance of the antioxidant system to control them have been widely studied (Becana et al., 2010). Likewise, the presence of $\cdot \mathrm{NO}$ in the nodule is well documented (Baudouin et al., 2006; Nagata et al., 2008; del Giudice et al., 2011; Cam et al., 2012; Fukudome et al., 2016, 2018; Calvo-Begueria et al., 2018). Due to its reactive nature, $\cdot \mathrm{NO}$ and other reactive nitrogen species (RNS) can also interfere with this plant-rhizobia communication.

In the specific interactions Lotus japonicus-Mesorhizobium loti and Medicago sativa-Ensifer meliloti, $\cdot \mathrm{NO}$ was observed to be induced in the roots of plants $4 \mathrm{~h}$ post-inoculation (hpi), suggesting that NO participates at early stages of the plantrhizobia interaction (Nagata et al., 2008). Interestingly, $\cdot \mathrm{NO}$ was only perceived at $4 \mathrm{hpi}$ but not at 10 and $24 \mathrm{hpi}$, and this effect was not observed when the roots were inoculated with unspecific rhizobium (Nagata et al., 2008). In contrast, $L$. japonicus showed a higher and sustained accumulation of $\cdot \mathrm{NO}$ in roots when infected with different plant pathogens (Nagata et al., 2008). These observations suggest that the peak response observed at $4 \mathrm{hpi}$ is a signal-recognition response, rather than a stress response. Different kinetics for $\cdot \mathrm{NO}$ accumulation were observed in the Medicago truncatula-E. meliloti symbiosis, but the results were consistent in the fact that $\cdot \mathrm{NO}$ is induced and necessary for the correct establishment of the symbiosis (del Giudice et al., 2011). In this symbiosis, the induction of $\mathrm{NO}$ was detected 2 days post-infection (dpi), during the curling of the root hair, and $6 \mathrm{dpi}$, when the infection thread is formed (del Giudice et al., 2011). Using reporter bacteria responsive to $\mathrm{NO}$, the authors showed that the bacteria respond 


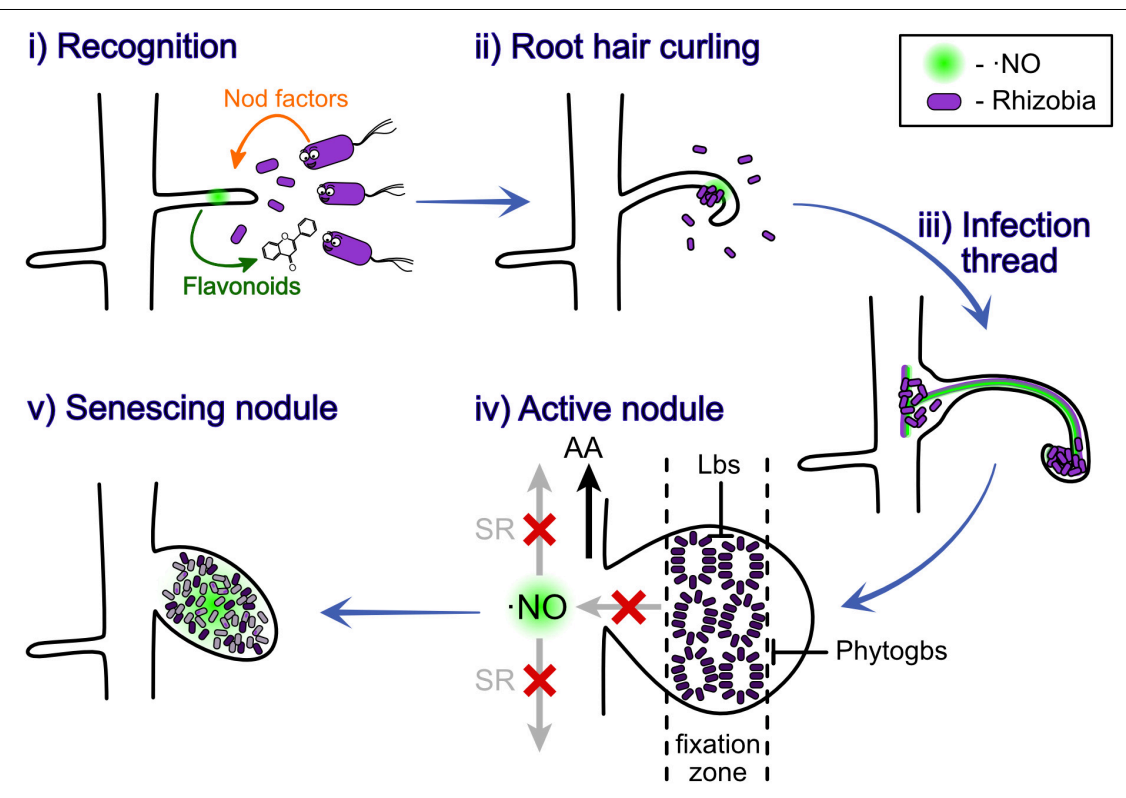

FIGURE 1 | Nitric oxide participates at different stages of the nodulation process. NO was observed to be involved at all the different stages of nodulation, plant-rhizobium recognition (i), root hair curling (ii), infection thread (iii), nitrogen fixation in active nodules (iv), and senescing nodules (v). The light purple indicates the bacteria; the dark purple indicates the bacteroids; the gray indicates dead bacteroids; and the diffuse light green indicates .NO. AA, amino acids; Phytogbs, PHYTOGLOBINS; Lbs, LEGHEMOGLOBINS; SR, systemic response.

to the endogenously produced $\cdot \mathrm{NO}$ in the infection pocket, and when $\cdot \mathrm{NO}$ is specifically scavenged, the development of the nodule is delayed (del Giudice et al., 2011). Together, this evidence demonstrates that $\cdot \mathrm{NO}$ promotes the legume-bacteria interaction and nodule development, potentially acting as a signaling molecule (discussed in section "Signaling Role of $\cdot \mathrm{NO}$ in Nitrogen Fixation").

At later stages of this symbiosis $\cdot \mathrm{NO}$ was also shown to be present in $M$. truncatula nodules, both in developing (10 dpi) and mature nodules (30 dpi), in particular, in the fixation zone (Baudouin et al., 2006). Furthermore, $\mathrm{NO}$ was observed to locally induce nodule senescence in M. truncatula (Cam et al., 2012) and L. japonicus (Fukudome et al., 2018). These findings suggest the involvement of $\cdot \mathrm{NO}$ also during nitrogen fixation and nodule senescence (Figure 1).

Taking all together, the current evidence clearly shows the involvement of $\cdot \mathrm{NO}$ during the legume-rhizobia interaction. In many cases, a positive effect of $\cdot \mathrm{NO}$ on this interaction is observed, although the mechanism is not fully understood (discussed in section "Perspectives").

\section{METABOLISM OF ·NO IN NODULES}

Plants can produce -NO by different ways, some of them non-enzymatic, as the non-enzymatic reduction of nitrite (Bethke et al., 2004), and others are dependent on enzymes such as the NITRATE REDUCTASE (NR), PLASMA MEMBRANE-BOUND NITRITE: ·NO REDUCTASE, mitochondrial-electron transport chain-dependent (mETCdependent) nitrite-reducing activity, and the NOS-like activity
(Stöhr et al., 2001; Planchet et al., 2005; Corpas et al., 2009; Astier et al., 2018). POLYAMINE OXIDASES and HYDROXYLAMINE OXIDASE have been also suggested to contribute to $\cdot \mathrm{NO}$ production (Tun et al., 2006; Rümer et al., 2009). Despite the several mechanisms involved in .NO production, the $\mathrm{NR}$ and mETC-dependent reduction of nitrite are the better understood mechanisms to contribute to $\mathrm{NO}$ production, being the latter only relevant under microoxic and anoxic conditions (León and Costa-Broseta, 2020). Interestingly, under the nodulation process, the three genes encoding for NR of $M$. truncatula were shown to be induced (Damiani et al., 2016). In fact, the authors suggested a specific role of these enzymes as .NO source in nodulation. Nonetheless, recent experiments coupling EPR (electron paramagnetic resonance) and DAF-2 (4,5-diaminofluorescein) to detect -NO in bean and soybean nodules suggested that $\cdot \mathrm{NO}$ is also produced by nitrate- and arginine-independent pathways (Calvo-Begueria et al., 2018).

Under microoxic conditions, it is well known that nitrite can be used as final electron acceptor of the mETC to produce $\cdot \mathrm{NO}$ (Horchani et al., 2010; Gupta and Igamberdiev, 2011). Therefore, once the nodule is established, the microoxic condition is generated within the nodule promoting this extra source of $\cdot \mathrm{NO}$. In this situation, $\cdot \mathrm{NO}$ is involved in the cycle named Phytoglobin-NO (Phytogb--NO), in which the $\cdot \mathrm{NO}$ produced from nitrite by the mETC diffuses into the cytosol where it is oxidized into nitrate by PHYTOGLOBINS (Phytogbs), and the resulting nitrate is reduced back to nitrite by NR and transported to the mitochondria where the cycle is repeated (Figure 2; Stoimenova et al., 2007; Igamberdiev et al., 2010; Gupta and Igamberdiev, 2011). This Phytogb--NO cycle was suggested to function as 


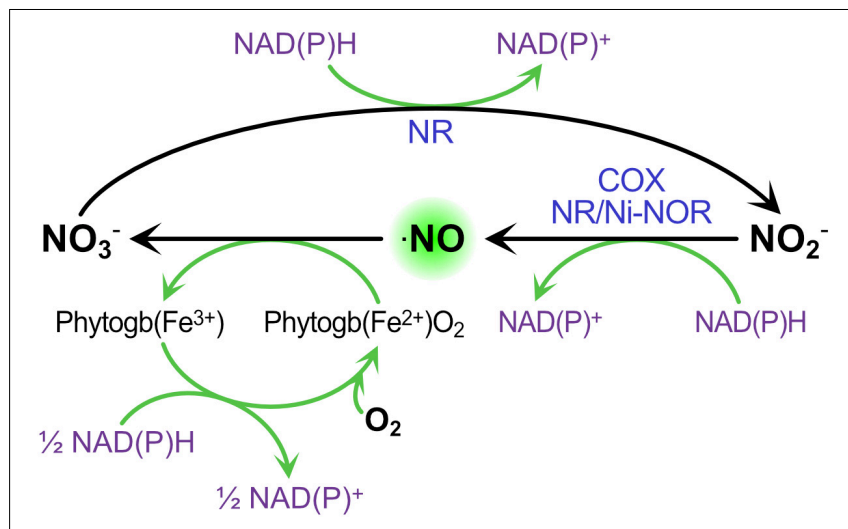

FIGURE 2 | The contribution of Phytogb/.NO cycle to $\cdot$ NO production and $\mathrm{NAD}(\mathrm{P}) \mathrm{H}$ re-oxidation during hypoxia. $\mathrm{NO}$ is oxidized to nitrate by OXYPHYTOGLOBIN [Phytogb $\left(\mathrm{Fe}_{2}{ }^{+}\right) \mathrm{O}_{2}$ ], which turns to METPHYTOGLOBIN $\left[\right.$ Phytogb $\left.\left(\mathrm{Fe}^{3+}\right)\right]$. Nitrate is then reduced to nitrite through NITRATE REDUCTASE (NR), and nitrite is reduced to .NO though NR, the PLASMA MEMBRANE NITRITE--NO REDUCATSE (NI-NOR) or the CYTOCHROME OXIDASE (COX). NAD(P)H oxidation occurs in the reactions forming . $\mathrm{NO}$ and its subsequent oxidation back to nitrate.

an alternative mechanism to the classic fermentation pathways (ethanol and lactate formation) for the re-oxidation of $\mathrm{NAD}(\mathrm{P}) \mathrm{H}$ to $\mathrm{NAD}(\mathrm{P})^{+}$during hypoxia (Igamberdiev and Hill, 2004). In microoxic cells, the energy production for short-term viability is achieved mainly through glycolysis. The Phytogb--NO cycle would allow NADH re-oxidation during the reduction of $\mathrm{NO}_{3}{ }^{-}$ to $\cdot \mathrm{NO}_{2}{ }^{-}$and in the regeneration of reduced $\left(\mathrm{Fe}^{2+}\right)$ Phytogb (Figure 2), being the resulting $\mathrm{NAD}^{+}$available for the glycolytic process (Igamberdiev and Hill, 2004).

Besides the electron transport chain of the nodule cells, the electron transport chain of some rhizobia also contributes to NO production (Horchani et al., 2010) through the denitrification pathway, being the highest contribution for $\cdot \mathrm{NO}$ biosynthesis from the bacteroid side (Hichri et al., 2015). In the Bradyrhizobium genera, different strains have been shown to be able to denitrify under microoxic conditions, both in free-living conditions (Monza et al., 2006) and in symbiosis (Bedmar et al., 2005). Under flooding conditions however, in soybean nodules, the periplasmic NR and NiR of Bradyrhizobium diazoefficiens (also known as Bradyrhizobium japonicum) were suggested to be the main sources of ·NO (Sánchez et al., 2010). Although the contribution of $\cdot \mathrm{NO}$ by the bacteria is considered to be lower than that by the plants (Baudouin et al., 2006; Horchani et al., 2010), both partners are involved in the production of this molecule in mature nodules. Therefore, it is not surprising that some genes involved in both $\cdot \mathrm{NO}$ production and degradation have proven to be more expressed in mature nodule when compared to developing nodule (Berger et al., 2019). This indeed suggests that a more active metabolism of $\cdot \mathrm{NO}$ takes place in established nodules.

Finally, it is important to remark that $\cdot \mathrm{NO}$ is highly permeable to biological membranes (permeability coefficient in the membrane of $93 \mathrm{~cm} \cdot \mathrm{s}^{-1}$, Signorelli et al., 2011), meaning that $\cdot \mathrm{NO}$ can diffuse in and out the bacteroids. Thus, the lack of a unique $\cdot \mathrm{NO}$ source together with its capacity to diffuse between the plant and the rhizobia set a complex scenario to elucidate the main source of $\cdot \mathrm{NO}$ in this interaction.

\section{S-NITROSOTHIOLS IN NODULE}

Nitric oxide can modulate the activity of different enzymes mainly through $S$-nitrosylation (also known as $S$-nitrosation). This reversible posttranslational modification of proteins is the covalent binding of a $\cdot \mathrm{NO}$ group to the thiol group of a cysteine residue leading to the formation of an $S$-nitrosothiol (SNO). Different mechanisms have been shown to mediate this modification, varying on the state of the cysteine (as radical or anion) and the nature of the $\mathrm{NO}$ group (as radical, anion, cation or transiently associated to other molecules) (Kovacs and Lindermayr, 2013). This modification produces structural changes in the protein, and when the modified residues are close enough to the active site, its activity is affected. The major effects of $\cdot \mathrm{NO}$ on biological processes are due to its capacity to induce post-translational modifications of key proteins involved in signaling cascade pathways, resulting in the up or downregulation of downstream components such as transcription factors, which in turn affect the expression of a plethora of genes. For instance, $\cdot \mathrm{NO}$ is known to inactivate several proteins involved in the ABA signaling pathway that controls the activity of the transcription factor ABI5, resulting in the suppression of the ABA-mediated responses (Signorelli and Considine, 2018). Likewise, $\cdot$ NO can target the group VII of ETHYLENE RESPONSE FACTORS (ERF) to proteasomal degradation (Gibbs et al., 2014), affecting the regulation of different process under regulation of these transcription factors, such as abiotic/biotic stress responses and developmental processes (Gibbs et al., 2015; Considine et al., 2017).

The inhibition of NITROGENASE by $\cdot \mathrm{NO}$ has been known since long time (Trinchant and Rigaud, 1982; Kato et al., 2010). Although this inhibition can be through the formation of metalnitrosyl complex (Michalski and Nicholas, 1987), in the symbiosis M. truncatula-E. meliloti two NITROGENASE proteins (encoded by $n i f K$ and $n i f H$ ) were reported to be $S$-nitrosylated (Puppo et al., 2013), which could present an alternative mechanism to post-translationally regulate the NITROGENASE activity in the bacteroids. In the same symbiosis, many proteins related to TCA cycle and carbohydrate metabolism were reported to be $S$-nitrosylated in both the legume and the partner rhizobium (Puppo et al., 2013). Moreover, in this legume three proteins involved in amino acid metabolism, the ASPARAGINE SYNTHETASE, GLUTAMINE SYNTHETASE, and S-ADENOSYLMETHIONINE SYNTHETASE were also reported as S-nitrosylated (Melo et al., 2011; Puppo et al., 2013). Although there have been some proteins identified as $S$-nitrosylated, in many cases the consequence of such modification on the enzymatic activity is still unknown. Conversely, the GLUTATHIONE PEROXIDASE 1 (GPX1) from nodules of $M$. truncatula is known to be reversibly inactivated by S-nitrosylation (Castella et al., 2017). As this enzyme participates in the transmission of redox signals, it was suggested that $\cdot \mathrm{NO}$ can exert part of its signaling function through the modulation of this protein (Castella et al., 2017). 
Nevertheless, it is important to remark that $\cdot \mathrm{NO}$ levels do not always correlate with SNOs levels. This was clearly observed in non-nodulated roots of the model legume L. japonicus (Signorelli et al., 2019) and in nodules of Arachis hypogaea (Maiti et al., 2012). Thus, low levels of $\cdot \mathrm{NO}$ do not necessarily implicate that $S$-nitrosylation will not take place. Moreover, in A. hypogaea nodules it was observed that the levels of cytoplasmic SNOs were lower in the nodule than in the symbiotic bacteria; thus the authors suggested that the bacteria contribute to the protection of $S$-nitrosylation in the nodule and that this interaction might implicate the transfer of redox compounds between the bacteroids and the nodule cells (Maiti et al., 2012). Also, the number of SNOs in the nodule was observed to increase with the age of the nodule (Maiti et al., 2012).

Interestingly, a phytogb (AHb1) from Arabidopsis thaliana was the first protein of plants reported to be $S$-nitrosylated and the authors suggested this could be a mechanism to eliminate -NO during hypoxic stress (Perazzolli et al., 2004). The authors also tested if the overexpression of $\mathrm{AHb} 1$ reduced the $\cdot \mathrm{NO}$ mediated hypersensitive cell death in response to pathogens, but it was not the case (Perazzolli et al., 2004). Conversely, the detoxification of SNOs was proven to increase disease resistance upon infection with Pseudomonas syringae (Feechan et al., 2005). Therefore, increased SNO levels are believed to enhance the susceptibility to pathogens and change the redox status of the cells resulting in the activation of antioxidant responses (BegaraMorales et al., 2019 and references therein). In this sense, it would be interesting to understand if changes in SNOs, prior to rhizobium infection, promote or reduce the success of the infection. Understanding this could lead to the use of better management practices to promote rhizobia inoculation.

Together, the evidence demonstrates that SNOs occurs in vivo in legume nodules and, in some cases, the activity of the proteins is affected by this posttranslational modification. In the near future, it is expected that an increased number of $S$-nitrosylated proteins are going to be reported. For those proteins that have been already reported as $S$-nitrosylated, it would be important to understand the consequences on their activity.

\section{ROS AND RNS HOMEOSTASIS IN THE NODULE}

\section{ROS and RNS Are Induced in the Establishment of the Legume-Rhizobia Interaction}

Reactive oxygen species are formed due to partial reductions of $\mathrm{O}_{2}$ and can react with cellular components leading to irreparable metabolic dysfunction or cell death. As ROS are ubiquitous in aerobic organisms, they tend to be controlled under normal conditions by different antioxidant systems. In such controlled conditions, ROS are essential for certain cellular functions. ROS include free radicals, such as superoxide radical $\left(\mathrm{O}_{2} \cdot{ }^{-}\right)$and hydroxyl radical $(\cdot \mathrm{OH})$, and non-radical compounds like hydrogen peroxide $\left(\mathrm{H}_{2} \mathrm{O}_{2}\right)$ and singlet oxygen $\left({ }^{1} \mathrm{O}_{2}\right)$. The term RNS is used to designate $\cdot \mathrm{NO}$ and related molecules such as peroxynitrite $\left(\mathrm{ONOO}^{-}\right)$, nitrogen dioxide $\left(\cdot \mathrm{NO}_{2}\right)$, dinitrogen trioxide $\left(\mathrm{N}_{2} \mathrm{O}_{3}\right)$ and SNOs. Like ROS, RNS can be moderately (e.g., .NO, SNOs) or highly (e.g., $\mathrm{ONOO}^{-}$, $\cdot \mathrm{NO}_{2}$ ) reactive. RNS, directly or indirectly, participate in the post-translational modifications of proteins, which are involved in the cellular signaling process in both physiological and pathological conditions.

During the plant-rhizobium interaction, ROS play an important role and its production by the plants is known to be triggered, at least in part, by compatible Nod factors (Ramu et al., 2002). The silencing of the apoplastic- $\mathrm{O}_{2} \cdot{ }^{-}$-producing enzyme, RESPIRATORY BURST OXIDASE HOMOLOG (RBOH), negatively affected the symbiotic nitrogen fixation in different legumes (Marino et al., 2011; Arthikala et al., 2017). The plants also respond producing a peroxidase (RIP1) as a mechanism to prevent the excessive generation of $\mathrm{H}_{2} \mathrm{O}_{2}$ (Ramu et al., 2002). Therefore, both the ROS generation and the induction of antioxidant system to control ROS levels are essential for the correct establishment of the symbiosis (Ramu et al., 2002; Becana et al., 2010). Legumes count with the common antioxidant enzymes such as SUPEROXIDE DISMUTASE, CATALASE, and diverse PEROXIDASES, and non-enzymatic antioxidants such as ascorbate and glutathione as the first barrier to protect against ROS. Here the general antioxidant machinery will not be discussed. Instead, we describe those systems specific from the legume-rhizobia symbiosis.

\section{Phytoglobins}

Nodule function requires the protein LEGHEMOGLOBIN (Lb), which transport and deliver $\mathrm{O}_{2}$ to the symbiosomes at a low but steady concentration that allows efficient bacteroid respiration while preventing NITROGENASE inactivation (Appleby and Bergersen, 1980). Besides Lbs, plants possess many other HEMOGLOBINS (Hbs), currently known as Phytogbs, which function is less clear in plants but have been linked to the control of RNS homeostasis (Dordas et al., 2003; Perazzolli et al., 2004; Nagata et al., 2008). Here, we introduce the different plant Hbs and their potential role in controlling ROS and RNS.

In vascular plants, Phytogbs can be divided into six types based on phylogenetic analyses and biochemical properties (Hill et al., 2016). Phytogb0 are localized in any organ of gymnosperms but also in algae and bryophytes, and have moderate to high affinity for $\mathrm{O}_{2}$ (Garrocho-Villegas and Arredondo-Peter, 2008). Phytogbs1 have extremely high $\mathrm{O}_{2}$ affinities, making them unsuitable for $\mathrm{O}_{2}$ transport and delivery (Smagghe et al., 2009), and their main function seems to be related to the modulation of -NO (Gupta et al., 2011b) and preserving cellular energy during hypoxia (Hill, 2012). In L. japonicus, the expression of Ljphytogb1-1 gene increases in response to symbiosis with $M$. loti, but not when it interacts with pathogenic microorganisms so it has been proposed that Ljphytogb1-1 eliminates the $\cdot \mathrm{NO}$ produced in the initial response to the infection, allowing the establishment of symbiosis (Nagata et al., 2008). Very recently, it has been shown in $M$. truncatula that Mtphytogb1-1 regulates the concentration of $\cdot \mathrm{NO}$ both during early symbiosis steps and in mature nodules (Berger et al., 2020). Phytogbs2 display $\mathrm{O}_{2}$ affinities that resemble those of Lbs (Dordas, 2009), and 
their expression is known to be induced by CK treatments and cold conditions (Hunt et al., 2001). Vigeolas et al. (2011) proposed that this type of Phytogbs could facilitate the supply of $\mathrm{O}_{2}$ to developing tissues. Phytogbs1 and Phytogbs 2 are localized in any organ of angiosperms. Phytogbs3 represent a group with very low similarity to Phytogbs1 and Phytogbs 2 and have moderate $\mathrm{O}_{2}$ affinities (Watts et al., 2001). A biochemical property that defines Phytogbs3 is that they have a 2-on-2 $\alpha$ helical sandwich secondary structure instead of the canonical 3-on-3 structure of other Phytogbs (Wittenberg et al., 2002). Although the functions of Phytogbs 3 are unknown, some of them are induced in nodules and mycorrhizal roots (Zhu et al., 2005) and might also interact with .NO (Sanz-Luque et al., 2015). It has been suggested in M. truncatula that the function of two Phytogbs3 could be related to symbiosis by suppressing the initial defensive response of the plant due to the ability of these proteins to bind -NO (Vieweg et al., 2005). In addition, some of their bacterial counterparts have been implicated in tolerance to nitrosative stress (Angelo et al., 2008). Both Lbs and SymPhytogb are proteins exclusively related to the symbiotic process facilitating a steady low $\mathrm{O}_{2}$ supply to the bacterial microsymbionts (Smagghe et al., 2009). They present moderate to high $\mathrm{O}_{2}$ affinity and are specifically localized in $\mathrm{N}_{2}$-fixing nodules of legumes and actinorhizal or any other non-legume plant, respectively.

\section{The Involvement of Plant Phytogbs in ROS and RNS Metabolism}

In nodules, high respiration rates together with a high concentration of $\mathrm{Lb}$ and the abundance of catalytic Fe enhance, among other things, nodule capacity to generate ROS (Marino et al., 2009). Using leghemoglobin-RNA interference lines of L. japonicus, Günther et al. (2007) demonstrated that loss of Lb results in significantly lower $\mathrm{H}_{2} \mathrm{O}_{2}$ levels in nodules, which suggested a role of $\mathrm{Lb}$ in in vivo ROS production. Like other Hbs, oxy- $\mathrm{Lb}\left(\mathrm{Lb}^{2+} \mathrm{O}_{2}\right)$ auto-oxidizes spontaneously to form ferric (or meta) $\mathrm{Lb}\left(\mathrm{Lb}^{3+}\right)$ and $\mathrm{O}_{2} \cdot{ }^{-}$, especially under the slightly acid $\mathrm{pH}$ of nodules (Puppo et al., 1981). The released $\mathrm{O}_{2}{ }^{-}$can, in turn, oxidize other oxy-Lb molecules to $\mathrm{Lb}^{3+}$, which enhances the inactivation of ferrous $\mathrm{Lb}\left(\mathrm{Lb}^{2+}\right)$ and oxy-Lb. Oxy-Lb and $\mathrm{Lb}^{3+}$ can also be oxidized by $\mathrm{H}_{2} \mathrm{O}_{2}$ (Puppo et al., 1982). The reaction between $\mathrm{H}_{2} \mathrm{O}_{2}$ and oxy-Lb or ferric $\mathrm{Lb}$, in equimolar proportion, forms ferryl $\mathrm{Lb}\left(\mathrm{Lb}^{I V}\right)$, a stable but inactive form of Lb (Aviram et al., 1978; Sievers et al., 1978). When Lb and $\mathrm{H}_{2} \mathrm{O}_{2}$ are in a 1:2 ratio, radicals can be formed in the Tyr residues of the protein, which react forming 2 types of compounds: a green derivative, originated by the covalent binding of the heme with the apoprotein, and a dimeric Lb, originated by an intramolecular Tyr-Tyr bond (Moreau et al., 1995).

Leghemoglobins are synthesized by the plants when they are colonized by a symbiotic rhizobium to scavenge the excess of $\mathrm{O}_{2}$ which can inhibit the NITROGENASE activity. Phytogbs exist in nodules but also in other organs like roots and leaves of all plants and their concentration range from $100 \mathrm{nM}$ under normal conditions to 5-20 $\mu \mathrm{M}$ when induced by different kind of stresses or hormones (Gupta et al., 2011a). Instead,
Lbs are found at millimolar concentrations in the nodules of legumes and are responsible for the typical red color of nodules (Gupta et al., 2011a).

All types of Phytogbs were shown to be highly expressed in $L$. japonicus nodules (Bustos-Sanmamed et al., 2011). Remarkably, LjPhytogb1-1, one protein of the Type 1 family, was proved to have an extremely high affinity for $\mathrm{O}_{2}(K=0.05 \mathrm{nM})$ (Sainz et al., 2013). Because of its high $\mathrm{O}_{2}$ affinity, this protein remains oxygenated and active even in the presence of CO. This may be important in nodules, where CO can be formed in significant amounts as result of the Lb degradation by heme oxygenases (Baudouin et al., 2004; Sainz et al., 2013). As evidenced in the L. japonicus Phytogb1 overexpressing lines (LjPhytogb1-1), these proteins were shown to have a positive effect on the activity of the nodule during the L. japonicus-M. loti symbiosis and to delay senescence (Fukudome et al., 2018).

In the case of RNS, there is no specific enzymatic systems to scavenge them. Thus, any non-specific system can be relevant to attenuate the deleterious effect of RNS. This is the case of Phytogbs, which can directly scavenge RNS in vitro (Herold and Puppo, 2005) and in vivo in nodules of soybean and L. japonicus (Navascues et al., 2012; Sainz et al., 2015). Interestingly, the $L$. japonicus genes of these Phytogbs were shown to be induced by -NO (Shimoda et al., 2005), suggesting a response to scavenge the excess of $\cdot \mathrm{NO}$. As $\cdot \mathrm{NO}$ was shown to be high in the nitrogen fixation zone of nodules, the scavenging of $\cdot \mathrm{NO}$ by Lbs was suggested to be key to prevent inactivation of NITROGENASE activity by $\cdot \mathrm{NO}$ (Puppo et al., 2013). Because the nitration of Lbs requires low $\mathrm{pH} 5.5$, which is more common in senescent nodules, the protection of Lbs against RNS may be more relevant in senescent nodules. Interestingly, both Lbs and Phytogbs can contribute to the generation of $\mathrm{NO}_{3}{ }^{-}$after scavenging $\cdot \mathrm{NO}$ and $\mathrm{O}_{2}$, with the concomitant oxidation of $\mathrm{Hb}^{2+} \mathrm{O}_{2}$ to $\mathrm{Hb}^{3+}$, by the cycle Phytogb-·NO mentioned above (Herold and Puppo, 2005; Berger et al., 2019).

\section{Bacterial Contribution to ROS and RNS Scavenging}

In the bacteria, a FLAVOPROTEIN and a SINGLE-DOMAIN HEMOGLOBIN from B. japonicum were shown to reduce cell death under the exposure to a $\cdot \mathrm{NO}$-donor, suggesting that these proteins are relevant to detoxify the excess of $\cdot \mathrm{NO}$ formed as a by-product of $\mathrm{NO}_{3}{ }^{-}$assimilation (Cabrera et al., 2015). In E. meliloti, a FLAVOHEMOGLOBIN (HMP) was shown to be one of the most important enzymes to detoxify -NO (Meilhoc et al., 2010; Cam et al., 2012).

Likewise, excessive ROS can be controlled by non-specific scavengers in the rhizobium. For instance, exopolysaccharides are produced in large amounts by Rhizobium leguminosarum bv. trifolii and play a significant protective role as a barrier against the ROS produced by the clover plants during the symbiotic interaction (Jaszek et al., 2014). Not only the ROS scavenging but also its production is a key factor to determine ROS cellular concentration. As mentioned above, ROS production in the legumes can be also regulated by the rhizobium through nodulation factors (Damiani et al., 2016). Understanding the 
mechanisms controlling ROS and RNS concentration in the plant-rhizobium interaction has been key to produce and use genetic tools that allow manipulating ROS and RNS levels and unrevealing their importance in this process.

\section{SIGNALING ROLE OF ·NO IN NITROGEN FIXATION}

Given the evidence that $\cdot \mathrm{NO}$ regulates the transcription of genes encoding for different NITROGENASE activity and that it can also modulate NITROGENASE activity at posttranslational level, it is clear that $\cdot \mathrm{NO}$ can play a signaling role in nitrogen fixation. The evidence presented here up to now has been focused on NITROGENASE and close related genes. However, we know that signaling molecules interact with signaling cascade pathways involving phytohormones.

Although there is a strong body of evidence suggesting a role of $\cdot \mathrm{NO}$ in the legume-rhizobia interaction, it is still not clear how -NO promotes this interaction. A potential mechanism includes the activation of $\mathrm{CK}$ signaling by $\cdot \mathrm{NO}$. In the M. truncatulaE. meliloti symbiosis, the gene encoding for the CK receptor CRE1 (CYTOKININ RESPONSE 1) of this legume, which is the sole receptor mediating CK signaling to induce nodulation (Gonzalez-Rizzo et al., 2006), was observed to be induced by -NO (Ferrarini et al., 2008; del Giudice et al., 2011). Downstream CK signaling, the transcription factors NODULE INCEPTION (NIN) and NODULATION SIGNALING PATHWAY 2 (NSP2) promote nodule development (Schauser et al., 1999; Murakami et al., 2007; Suzaki et al., 2012). Thus, the induction of CRE1 by $\cdot \mathrm{NO}$ illustrates a potential mechanism by which the -NO produced soon after the infection could promote the establishment of the symbiosis at early stages (Figure 3).

Auxin accumulation is also important for nodule development, and both flavonoid and CK inhibit AUX transport to promote AUX accumulation in proliferating cortical cells (Suzaki et al., 2012). Based on evidence showing that -NO down-regulate the expression of PIN AUX efflux carriers genes in arabidopsis and rice, Berger et al. (2019) suggested that ·NO can also contribute to the control of AUX transport by repressing the expression of PIN proteins to produce AUX accumulation and ultimately cell division in the nodule (Figure 3). Yet, it is not clear the mechanism by which $\cdot \mathrm{NO}$ can regulate PIN levels. A potential mechanism can be through the $\cdot$ NO-induced CK signaling mentioned above (via CRE 1). CK was shown to control the PIN proteins and its degradation to redirect AUX efflux and establish local AUX accumulation (Plet et al., 2011; Marhavý et al., 2014). Through this mechanism, the NO-induced CK signaling could contribute to reducing PIN levels (Figure 3). In future research, it would be interesting to evaluate at protein level if CRE1 is induced by $\cdot \mathrm{NO}$.

Abscisic acid (ABA) plays an important role in plant development and has been shown to negatively affect nodule development at different stages in several legumes (Phillips, 1971; Suzuki et al., 2004; Tominaga et al., 2009, 2010; Nagata and Suzuki, 2014). For instance, in the L. japonicus ABAinsensitive mutant enf1 (enhanced nitrogen fixation 1), both

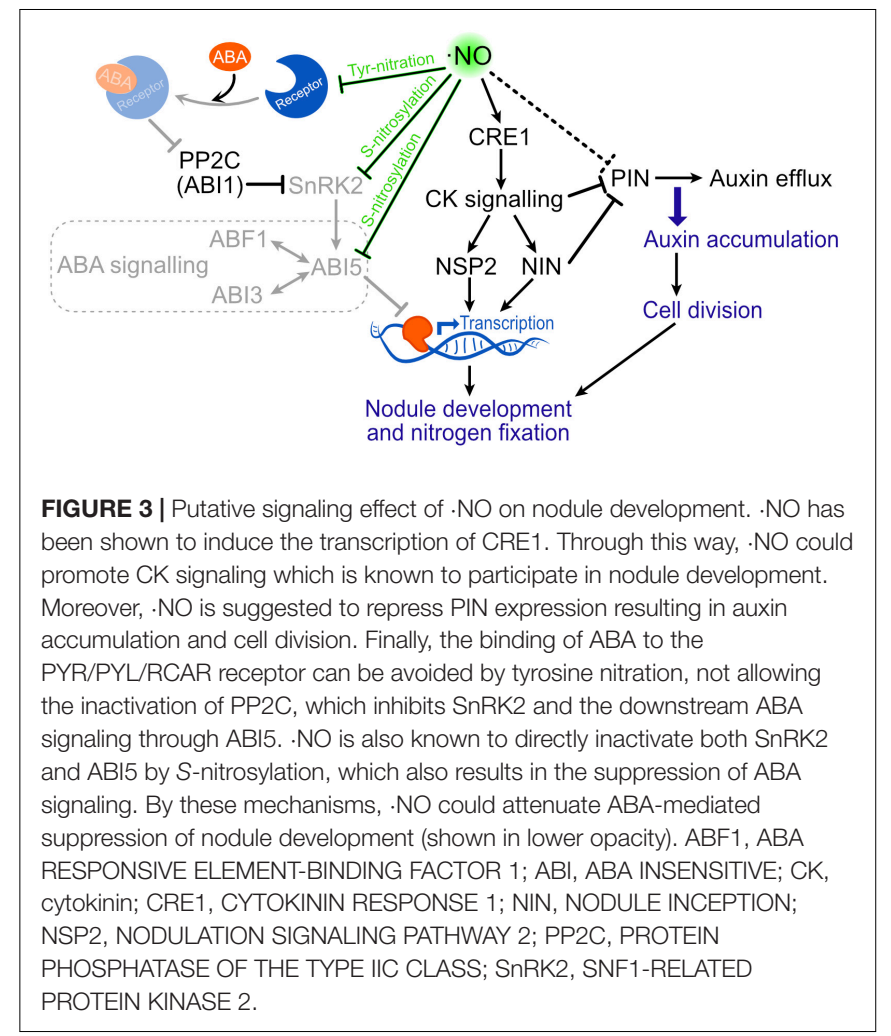

the nitrogen fixation and the number of nodules formed were almost double (Tominaga et al., 2009), suggesting that ABA inhibits nodule formation and nitrogen fixation. Accordingly, when $L$. japonicus WT plants were treated with an inhibitor of ABA synthesis, the number of nodule and nitrogen fixation activity was increased (Tominaga et al., 2010). This negative effect of ABA was related to its capacity to inhibit CK signaling, isoflavonoid synthesis and the calcium spiking produced after Nod-factor perception (Miwa et al., 2006; Ding et al., 2008; Tominaga et al., 2010; Nagata and Suzuki, 2014). M. truncatula lines over expressing the A. thaliana abil-1 allele, which codifies for the PROTEIN PHOSPHATASE OF THE TYPE IIC CLASS (PP2C) that is able to inhibit ABA signaling (Figure 3), showed hypernodulation phenotype (Ding et al., 2008). In this line, ABA was shown to suppress Nod-factor signal transduction and CK induction (Ding et al., 2008). The inhibition of ABA signaling by $\mathrm{PP} 2 \mathrm{C}$ is through its capacity to dephosphorylate and inactivate the serine/threonine kinases SnRK2. In a similar way, $\mathrm{NO}$ was shown to be able to inactivate some family members of the SnRK2 kinases by $S$-nitrosylation (Wang et al., $2015 \mathrm{a}, \mathrm{b})$. Moreover, $\cdot \mathrm{NO}$ was shown to negatively regulate ABA signaling up- and down-stream SnrK2 (Figure 3; Albertos et al., 2015; Castillo et al., 2015; Wang et al., 2015a). Considering that $\cdot \mathrm{NO}$ production is enhanced during the legume-rhizobia interaction (Figure 1), it is expected that in such situation the ABA signaling pathway will be more prone to be affected by -NO (Figure 3).

Besides affecting the response of hormones directly involved in nodule development (i.e., $\mathrm{CK}$ and AUX), $\cdot \mathrm{NO}$ also modulates 
the response to salicylic acid (SA) (Klessig et al., 2000) and jasmonic acid (JA) (Huang et al., 2004), two hormones known to be involved in the innate immune response of plants (Betsuyaku et al., 2018; Tarkowski et al., 2020). Thus, it has been considered that by modulating the plant innate immune response $\cdot \mathrm{NO}$ could potentially modulate the establishment of the symbiosis (Tartaglia et al., 2019). In M. truncatula and L. japonicus, the SA-mediated plant defense pathways were shown to inhibit the formation of determinate- and indeterminate-type of nodules (Stacey et al., 2006). Regarding JA however, there is no clear evidence that it can modulate nodule development, in fact, transgenic plants over-expressing and silencing an enzyme of the JA biosynthesis (ALLENE OXIDE CYCLASE) were unable to affect development and function of nodules (Zdyb et al., 2011). It is not surprising that $\cdot \mathrm{NO}$ had a differential effect on SA and JA signaling, as SA and JA usually have a mutually antagonist effect (Betsuyaku et al., 2018). Further research would contribute to understand the importance of the innate immune response of plants in the legume-rhizobia interaction and how relevant $\cdot \mathrm{NO}$ is to this process.

\section{PERSPECTIVES}

\section{The Effects of $\cdot \mathrm{NO}$ on Nitrogen Fixation}

Different reports have suggested that NO can both promote and reduce nitrogen fixation. Although the conclusions in some cases are opposite, the results are not necessarily opposite. Furthermore, the effect of $\cdot \mathrm{NO}$ on nitrogen fixation depends on whether it acts directly on the NITROGENASE, or on upstream effectors, the concentration of $\cdot \mathrm{NO}$ and the time of the exposure. In this section, we will refer first to the evidence concluding a positive effect of $\cdot \mathrm{NO}$ on nitrogen fixation, followed by those suggesting a negative effect.

\section{Positive Effects of $\cdot \mathrm{NO}$ on Nitrogen Fixation}

As presented above in section " $\mathrm{NO}$ in Legume-Bacteria Interaction", different works have concluded that $\cdot \mathrm{NO}$ is necessary for the correct establishment of the legume-rhizobia interaction and nodule development. This would ultimately result in better nitrogen fixation and thus can be considered as evidence supporting a positive effect of $\cdot \mathrm{NO}$ on BNF. Here, we discussed the potential mechanisms by which NO can have this effect, involving CK and AUX signaling pathways (Figure 3). Even before the legume-rhizobia interaction takes place, greater -NO levels were suggested to repress plant defense reactions which in turn would promote the correct infection and nodule establishment (Berger et al., 2019). This would be another mechanism by which $\cdot \mathrm{NO}$ promotes BNF.

Nitric oxide levels can also modulate the NITROGENASE activity and in this way directly affect nitrogen fixation. Treatments of $0.1 \mathrm{mM}$ sodium nitroprusside (SNP, $\cdot \mathrm{NO}$ donor) increased the NITROGENASE activity from L. japonicus nodules after $27 \mathrm{~h}$ by an unknown mechanism (Kato et al., 2010). As it is widely known that $\cdot \mathrm{NO}$ directly inhibits the NITROGENASE activity, we interpret these results as a positive effect on upstream effectors, that results in a greater NITROGENASE expression or activity (Figure 4A). Understanding this mechanism can shed light on key molecules controlling NITROGENASE activity.

\section{Negative Effects of - NO on Nitrogen Fixation}

Some reports have suggested that $\cdot \mathrm{NO}$ can difficult the establishment of the legume-rhizobia interaction. For instance, $L$. japonicus plants treated with $\cdot \mathrm{NO}$ donors and lines having higher -NO levels, due to a mutation in the Phytogb1 gene, were shown to have problems to form the infection threat (Fukudome et al., 2016). Moreover, they observed lower number of nodule in the lines having increased - NO levels (Fukudome et al., 2016). At first sight, this would be contradictory than other reports showing a
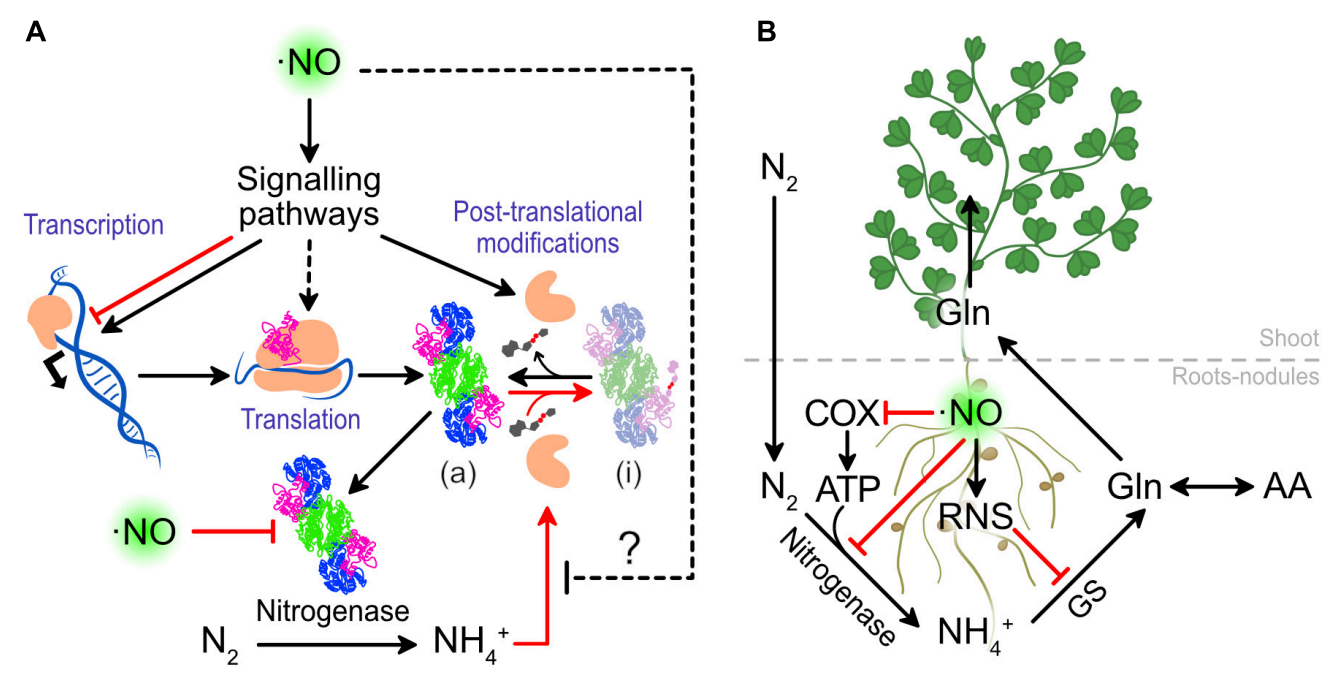

FIGURE 4 | The effect of ·NO on nitrogen fixation and assimilation. (A) Effects of .NO on NITROGENASE activity. (B) Detrimental effects of .NO and RNS on nitrogen fixation and assimilation. In red are presented the interactions that lead to a lower nitrogen fixation and assimilation. COX, CYTOCHROME OXIDASE; GS, GLUTAMINE SYNTHASE. 
positive effect of the $\mathrm{NO}$ in the infection thread formation (Pii et al., 2007; del Giudice et al., 2011), but it may mean that altering the equilibrium of $\cdot \mathrm{NO}$, either to more or less, always results in negative effect on the infection thread formation, which in some cases was interpreted as $\cdot \mathrm{NO}$ promoting the process and in other as inhibiting it.

The clearest negative effect of $\cdot \mathrm{NO}$ on nitrogen fixation is its capacity to inhibit NITROGENASE activity. The same authors who demonstrated in L. japonicus that $\cdot \mathrm{NO}$ enhances NITROGENASE activity when the nodules are treated with the $0.1 \mathrm{mM}$ SNP, also showed that at higher concentrations (at $1 \mathrm{mM}$ or above) SNP inhibits its activity (Kato et al., 2010). This was previously observed in vitro using NITROGENASE isolated from bacteroids of soybean nodules (Trinchant and Rigaud, 1982). This in vitro evidence demonstrates that $\cdot \mathrm{NO}$ can directly interact and inhibit NITROGENASE activity (Figure 4), independently of signaling events acting up-stream.

Besides the direct effect of $\cdot \mathrm{NO}$ on NITROGENASE, -NO was also suggested to attenuate NITROGENASE activity at the transcriptional level in B. japonicum (Sánchez et al., 2010). In particular, nodules of soybean subjected to flooding increased the NO content due to a higher periplasmic NR (Nap) activity, and in such situation, a down-regulation of the expression of B. japonicum nifH gene, which encodes the Fe subunit of the NITROGENASE, was observed (Sánchez et al., 2010).

Because plant Hbs and bacterial HMP were shown to be important $\cdot \mathrm{NO}$-detoxifying proteins in plants and rhizobia, respectively, different works used mutants and/or overexpressing lines for these proteins to control the endogenous levels of -NO. From the plant side, Hbs overexpression in L. japonicus resulted in lower .NO levels, a greater number of formed nodules and higher NITROGENASE activity, suggesting that basal levels of .NO inhibit nitrogen fixation (Shimoda et al., 2009). From the bacterial side, Cam et al. (2012) used E. meliloti Hmp null mutant strain and Hmp overexpressing strain to infect $M$. truncatula nodules and manipulate the levels of -NO. Through this approach, they showed that the Hmp null mutant had greater $\mathrm{NO}$ levels and a dramatic decrease in the NITROGENASE activity (Cam et al., 2012). They also found that nodule senescence was faster and greater in the Hmp null mutant, but smaller in the Hmp overexpressing strain (Cam et al., 2012). In this way, Cam et al. (2012) showed that keeping -NO under control is not only important to protect NITROGENASE activity, but also to delay nodule senescence which ultimately will result in extended nitrogen fixation by the plant.

Together, the current evidence demonstrates how $\cdot$ NO can regulate NITROGENASE activity not only at the transcriptional level but also at post-translational level (Figure 4A), and both the plants and the rhizobia play an important role controlling $\cdot$ NO homeostasis.

\section{The Effects of $\cdot \mathrm{NO}$ and RNS on Nitrogen Fixation and Assimilation \\ Beyond the effect of $\cdot \mathrm{NO}$ on NITROGENASE, $\cdot \mathrm{NO}$ is known to inhibit CYTOCHROME OXIDASE in different organisms including plants (Millar and Day, 1996). Thus, at high levels, -NO can threat the ATP production which is necessary for large}

quantities for NITROGENASE activity (Figure 4B). In such a situation, the ALTERNATIVE OXIDASE (AOX) of nodules was suggested to play a role to allow nodule respiration (Millar et al., 1997), although ATP production would be still minimized.

Once the nitrogen is reduced to ammonium by the rhizobia, the plants assimilate the ammonium to transport the nitrogen in an organic form and reduce the levels of free ammonium which is toxic at high concentrations. The GLUTAMINE SYNTHETASE-GLUTAMATE SYNTHASE (GS-GOGAT) plays a major role in the assimilation of $\mathrm{N}$ to amino acids. The GLUTAMINE SYNTHASE 1 of legumes was shown to be nitrated, both in roots of $L$. japonicus under drought stress (Signorelli et al., 2019) and in nodules of M. truncatula (Melo et al., 2011), causing the inactivation of the enzyme (Melo et al., 2011). As protein nitration requires $\cdot \mathrm{NO}$ and ROS, we can assume that uncontrolled .NO would not only inhibit NITROGENASE and cytochrome oxidase activity but also GLUTAMINE SYNTHETASE, compromising the total capacity of the legumes to reduce and assimilate atmospheric nitrogen (Figure 4B).

\section{Our Conclusions on the Effect of $\cdot \mathrm{NO}$ on Nitrogen Fixation and Assimilation}

Taking all together, the current evidence suggests that the positive effect of $\cdot \mathrm{NO}$ on nitrogen fixation is associated to the promotion of legume-rhizobia interaction and signaling pathways controlling the NITROGENASE activity (Figures 1, $3,4 \mathbf{A})$. On the other hand, the negative effects of $\cdot \mathrm{NO}$ on nitrogen fixation and assimilation seem to be mostly related to the direct inactivation of the main actors in the process of nitrogen fixation and assimilation by ·NO and RNS (Figure 4). Therefore, most of the evidence showing a negative effect of $\cdot \mathrm{NO}$ on BNF relay on the direct action of $\cdot \mathrm{NO}$ (or RNS) in a one to one ratio (e.g., CYTOCHOROME OXIDASE and NITROGENASE inactivation), whereas those linked to a positive effect seem to act on signaling pathways (e.g., CK, AUX, ABA) having an amplifier effect. Therefore, we speculate that, at physiological conditions, -NO is more likely to have a positive effect on BNF.

Both plants and rhizobia $\cdot \mathrm{NO}$-detoxifying systems were observed to be essential to control $\cdot \mathrm{NO}$ at basal levels and avoid NITROGENASE inactivation. The induction of early nodule senescence observed in different reports suggests that an early and uncontrolled increase of $\cdot \mathrm{NO}$ in the nodule can present a threat for plant productivity. In the experiments mentioned in this review, the levels of $\cdot \mathrm{NO}$ were manipulated to be abnormal, either using $\cdot \mathrm{NO}$ donors, mutant plants or rhizobium strains. However, we know that in wild type plants, levels of .NO can be triggered by environmental factors. Therefore, it seems to be important to understand how to prevent the spikes of $\cdot \mathrm{NO}$ that can threat the biological fixation and nodule viability.

\section{Alternative Signaling Pathways by Which -NO Could Modulate BNF}

The N-end rule pathway of proteolysis (NERP) is a mechanism by which $\mathrm{O}_{2}$, and also $\cdot \mathrm{NO}$, can act as signaling molecules to 
promote protein degradation. In particular in plants, some ERF were shown to be subjected to proteasomal degradation under normoxia through this pathway (Gibbs et al., 2014; Meitha et al., 2018). As the nodule also has a low $\mathrm{O}_{2}$ environment, ERF would be stable in such organ becoming a potential molecular switch that can be regulated by $\cdot \mathrm{NO}$ via the NERP. Therefore, evaluating the involvement of ERF in nodule seems to be a worth exploring area in the future.

Likewise, most research about ABA signaling has been focused on the control of dormancy in seeds or, at vegetative level, on stress responses, thus it is not clear yet which transcriptions factors could be involved downstream SnRK2 in nodulation. The basic leucine zipper transcription factor ABSCISIC ACID INSENSITIVE 5 (ABI5) is suggested to be the integrator of ABA and other phytohormone signaling during stress conditions and developmental processes (Skubacz et al., 2016). For example, $\mathrm{CK}$ is known to negatively regulate ABI5 protein level (Guan et al., 2014). Therefore, it would not be surprising that ABI5 also controls nodule formation. Currently, the role of ABI5 in nodule development is largely unexplored and further research in this direction would contribute to a better understanding of the molecular mechanism underpinning nodule development by phytohormones.

Finally, most of our knowledge about NITROGENASE regulation is limited to the transcriptional regulation of nif genes. However, in many nitrogen-fixing bacteria, the NITROGENASE is known to be regulated by post-translational modifications (Pope et al., 1985; Huergo et al., 2009; Heiniger et al., 2012). In particular, in the presence of ammonium, an ADP-ribosyltransfease (DraT2) transfers an ADP-ribose to a conserved arginine on DINITROGENASE REDUCTASE (NifH) to inactivate the NITROGENASE activity (Heiniger et al., 2012). This post-translational regulation involves several proteins such as $\mathrm{NtrB}, \mathrm{NtrC}, \mathrm{GlnK} 2, \mathrm{DraG}$, which if inactivated by $\cdot \mathrm{NO}$ would promote the NITROGENASE activity by interfering with the inactivation of NITROGENASE in presence of ammonium (Figure 4A). Therefore, this seems worth exploring because understanding the effect of $\cdot \mathrm{NO}$ on these proteins could led to potential mechanisms by which $\cdot \mathrm{NO}$ could modulate the posttranslational inhibition of the NITROGENASE activity.

\section{What Is the Role of Abiotic Stress-Induced .NO on BNF?}

The establishment of the nodule and BNF are known to be extremely sensitive to modest drought conditions in many species (Serraj et al., 1999; Sinclair and Serraj, 1995). Because of that, there have been many reports focused on how drought and other environmental factors affect BNF. However, there are virtually no studies about the effect of endogenous

\section{REFERENCES}

Albertos, P., Romero-Puertas, M. C., Tatematsu, K., Mateos, I., Sánchez-Vicente, I., Nambara, E., et al. (2015). S-nitrosylation triggers ABI5 degradation to promote seed germination and seedling growth. Nat. Commun. 6:8669. doi: $10.1038 /$ ncomms 9669 abiotic stress-induced $\cdot \mathrm{NO}$ on BNF. It would be interesting to evaluate this because most environmental stresses result in the overproduction of $\cdot \mathrm{NO}$ and nitrosative stress. For instance, in the legumes L. japonicus and Pisum sativum an overproduction of $\mathrm{NO}$ in roots was reported when they are exposed to environmental stresses (Signorelli et al., 2013; Lehotai et al., 2016). However, in these studies, the plants were grown in a medium having high levels of nitrate $\left(\mathrm{NO}_{3}{ }^{-}\right)$, which can be used by NR and contribute to $\mathrm{NO}$ overproduction. This does not represent a situation in which nodulation would take place, as it requires low levels of $\mathrm{N}$ in the soil, and perhaps in such conditions, there is no $\cdot \mathrm{NO}$ overproduction. Therefore, it would be important to evaluate if there is $\mathrm{NO}$ overproduction in nodulation and stress conditions, and what the effects of scavenging this $\cdot \mathrm{NO}$ are.

\section{CONCLUSION}

The involvement of $\mathrm{NO}$ throughout the whole process of legume-rhizobia interaction has been well documented, and most reports agree that $\cdot \mathrm{NO}$ is necessary for the correct establishment of the interaction. Both the bacteria and the plants have been shown to contribute to $\mathrm{NO}$ production and scavenging, and some findings points to the possibility that $\cdot \mathrm{NO}$ could promote the nodule formation by enhancing $\mathrm{CK}$ signaling pathway and interfere with AUX and ABA signaling pathways. Moreover, transcriptomic analyses have suggested that its metabolism is more active during nodule maturation. In mature nodules, many proteins have been identified as S-nitrosylated, including the thiol peroxidase GPX1 which is key for $\mathrm{H}_{2} \mathrm{O}_{2}$ sensing and transmission of oxidative signals. It is likely that this type of post-translational modification is the most responsible for the regulatory role of -NO. To counteract this modification, legume plants possess different hemoglobins which play a significant role in ROS and RNS metabolism by contributing to ROS production and $\cdot \mathrm{NO}$ scavenging. In the near future, it is likely that we expand our knowledge about enzymes that are S-nitrosylated in vivo and the effect of such modification.

\section{AUTHOR CONTRIBUTIONS}

SS conceived the idea and structure of the manuscript, wrote the first draft of the manuscript, and illustrated all the figures. ST$\mathrm{D}$ contributed to the section of metabolism of $\cdot \mathrm{NO}$ in nodules. MS contributed to the writing of the section about ROS and RNS homeostasis in the nodule and designed Figure 2. JM revised the whole manuscript.

Angelo, M., Hausladen, A., Singel, D. J., and Stamler, J. S. (2008). Interactions of NO with hemoglobin: from microbes to man. Methods Enzymol. 436, 131-168. doi: 10.1016/S0076-6879(08)36008-X

Appleby, C. A., and Bergersen, F. J. (1980). "Preparation and experimental use of leghaemoglobin," in Methods for Evaluating Biological Nitrogen Fixation, ed. F. J. Bergersen (Chichester: Wiley), 315-335. 
Arthikala, M. K., Montiel, J., Sánchez-López, R., Nava, N., Cárdenas, L., and Quinto, C. (2017). Respiratory burst oxidase homolog gene a is crucial for rhizobium infection and nodule maturation and function in common bean. Front. Plant Sci. 8:2003. doi: 10.3389/fpls.2017.02003

Astier, J., Gross, I., and Durner, J. (2018). Nitric oxide production in plants: an update. J. Exp. Bot. 69, 3401-3411. doi: 10.1093/jxb/erx420

Aviram, I., Wittenberg, B. A., Wittenberg, J. B., Wittenberg, A., and Wittenberg, J. B. (1978). The reaction of ferrous leghemoglobin with hydrogen peroxide to form leghemoglobin (IV). J. Biol. Chem. 253, 5685-5689.

Baudouin, E., Frendo, P., Le Gleuher, M., and Puppo, A. (2004). A Medicago sativa haem oxygenase gene is preferentially expressed in root nodules. J. Exp. Bot. 55, 43-47. doi: 10.1093/jxb/erh020

Baudouin, E., Pieuchot, L., Engler, G., Pauly, N., and Puppo, A. (2006). Nitric oxide is formed in Medicago truncatula-Sinorhizobium meliloti functional nodules. Mol. Plant Microbe Interact. 19, 970-975.

Becana, M., Matamoros, M. A., Udvardi, M., and Dalton, D. A. (2010). Recent insights into antioxidant defenses of legume root nodules. New Phytol. 188, 960-976. doi: 10.1111/j.1469-8137.2010.03512.x

Bedmar, E. J., Robles, E. F., and Delgado, M. J. (2005). The complete denitrification pathway of the symbiotic, nitrogen-fixing bacterium Bradyrhizobium japonicum. Biochem. Soc. Trans. 33, 141-144. doi: 10.1042/bst0330141

Begara-Morales, J. C., Chaki, M., Valderrama, R., Mata-Pérez, C., Padilla, M. N., and Barroso, J. B. (2019). The function of S-nitrosothiols during abiotic stress in plants. J. Exp. Bot. 70, 4429-4439. doi: 10.1093/jxb/erz197

Berger, A., Boscari, A., Frendo, P., and Brouquisse, R. (2019). Nitric oxide signaling, metabolism and toxicity in nitrogen-fixing symbiosis. J. Exp. Bot. 70, 4505-4520. doi: 10.1093/jxb/erz159

Berger, A., Guinand, S., Boscari, A., Puppo, A., and Brouquisse, R. (2020). Medicago truncatula Phytoglobin 1.1 controls symbiotic nodulation and nitrogen fixation via the regulation of nitric oxide concentration. New Phytol. doi: 10.1111/nph.16462

Bethke, P. C., Badger, M. R., and Jones, R. L. (2004). Apoplastic synthesis of nitric oxide by plant tissues. Plant Cell 16, 332-341. doi: 10.1105/tpc.017822

Betsuyaku, S., Katou, S., Takebayashi, Y., Sakakibara, H., Nomura, N., and Fukuda, H. (2018). Salicylic acid and jasmonic acid pathways are activated in spatially different domains around the infection site during effector-triggered immunity in Arabidopsis thaliana. Plant Cell Physiol. 59, 8-16. doi: 10.1093/pcp/pcx181

Bustos-Sanmamed, P., Tovar-Méndez, A., Crespi, M., Sato, S., Tabata, S., and Becana, M. (2011). Regulation of nonsymbiotic and truncated hemoglobin genes of Lotus japonicus in plant organs and in response to nitric oxide and hormones. New Phytol. 189, 765-776. doi: 10.1111/j.1469-8137.2010. 03527.x

Cabrera, J. J., Salas, A., Torres, M. J., Bedmar, E. J., Richardson, D. J., Gates, A. J., et al. (2015). An integrated biochemical system for nitrate assimilation and nitric oxide detoxification in Bradyrhizobium japonicum. Biochem. J. 473, 297-309. doi: 10.1042/bj20150880

Calvo-Begueria, L., Rubio, M. C., Martínez, J. I., Pérez-Rontomé, C., Delgado, M. J., Bedmar, E. J., et al. (2018). Redefining nitric oxide production in legume nodules through complementary insights from electron paramagnetic resonance spectroscopy and specific fluorescent probes. J. Exp. Bot. 69, 3703-3714. doi: 10.1093/jxb/ery159

Cam, Y., Pierre, O., Boncompagni, E., Hérouart, D., Meilhoc, E., and Bruand, C. (2012). Nitric oxide (NO): a key player in the senescence of Medicago truncatula root nodules. New Phytol. 196, 548-560. doi: 10.1111/j.1469-8137.2012. 04282.x

Castella, C., Mirtziou, I., Seassau, A., Boscari, A., Montrichard, F., Papadopoulou, K., et al. (2017). Post-translational modifications of Medicago truncatula glutathione peroxidase 1 induced by nitric oxide. Nitric Oxide 68, 125-136. doi: 10.1016/j.niox.2017.02.004

Castillo, M.-C., Lozano-Juste, J., Gonzalez-Guzman, M., Rodriguez, L., Rodriguez, P. L., and Leon, J. (2015). Inactivation of PYR/PYL/RCAR ABA receptors by tyrosine nitration may enable rapid inhibition of ABA signaling by nitric oxide in plants. Sci. Signal. 8:ra89. doi: 10.1126/scisignal.aaa7981

Chaki, M., Alvarez de Morales, P., Ruiz, C., Begara-Morales, J. C., Barroso, J. B., Corpas, F. J., et al. (2015). Ripening of pepper (Capsicum annuum) fruit is characterized by an enhancement of protein tyrosine nitration. Ann. Bot. 116, 637-647. doi: 10.1093/aob/mcv016
Cocking, E. C., Stone, P. J., and Davey, M. R. (2006). Intracellular colonization of roots of Arabidopsis and crop plants by Gluconacetobacter diazotrophicus. In Vitro Cell. Dev. Biol. Plant 42, 74-82. doi: 10.1079/IVP2005716

Considine, M. J., Diaz-Vivancos, P., Kerchev, P., Signorelli, S., Agudelo-Romero, P., Gibbs, D. J., et al. (2017). Learning to breathe: developmental phase transitions in oxygen status. Trends Plant Sci. 22, 140-153. doi: 10.1016/j.tplants.2016. 11.013

Corpas, F. J., Chaki, M., Fernandez-Ocana, A., Valderrama, R., Palma, J. M., Carreras, A., et al. (2008). Metabolism of reactive nitrogen species in pea plants under abiotic stress conditions. Plant Cell Physiol. 49, 1711-1722. doi: 10.1093/ pcp/pcn 144

Corpas, F. J., Leterrier, M., Valderrama, R., Airaki, M., Chaki, M., Palma, J. M., et al. (2011). Nitric oxide imbalance provokes a nitrosative response in plants under abiotic stress. Plant Sci. 181, 604-611. doi: 10.1016/j.plantsci.2011.04.005

Corpas, F. J., Palma, J. M., Del Rio, L., and Barroso, J. B. (2009). Evidence supporting the existence of l-arginine-dependent nitric oxide synthase activity in plants. New Phytol. 184, 9-14. doi: 10.1111/j.1469-8137.2009.02989.x

Damiani, I., Pauly, N., Puppo, A., Brouquisse, R., and Boscari, A. (2016). Reactive oxygen species and nitric oxide control early steps of the legume - rhizobium symbiotic interaction. Front. Plant Sci. 7:454. doi: 10.3389/fpls.2016.00454

del Giudice, J., Cam, Y., Damiani, I., Fung-Chat, F., Meilhoc, E., Bruand, C., et al. (2011). Nitric oxide is required for an optimal establishment of the Medicago truncatula-Sinorhizobium meliloti symbiosis. New Phytol. 191, 405-417. doi: 10.1111/j.1469-8137.2011.03693.x

Ding, Y., Kalo, P., Yendrek, C., Sun, J., Liang, Y., Marsh, J. F., et al. (2008). Abscisic acid coordinates nod factor and cytokinin signaling during the regulation of nodulation in Medicago truncatula. Plant Cell 20, 2681-2695. doi: 10.1105/tpc. 108.061739

Dordas, C. (2009). Nonsymbiotic hemoglobins and stress tolerance in plants. Plant Sci. 176, 433-440. doi: 10.1016/j.plantsci.2009.01.003

Dordas, C., Hasinoff, B. B., Igamberdiev, A. U., Manac'h, N., Rivoal, J., and Hill, R. D. (2003). Expression of a stress-induced hemoglobin affects NO levels produced by alfalfa root cultures under hypoxic stress. Plant J. 35, 763-770. doi: 10.1046/j.1365-313X.2003.01846.x

Feechan, A., Kwon, E., Yun, B. W., Wang, Y., Pallas, J. A., and Loake, G. J. (2005). A central role for S-nitrosothiols in plant disease resistance. Proc. Natl. Acad. Sci. U.S.A. 102, 8054-8059. doi: 10.1073/pnas.0501456102

Ferrarini, A., De Stefano, M., Baudouin, E., Pucciariello, C., Polverari, A., Puppo, A., et al. (2008). Expression of Medicago truncatula genes responsive to nitric oxide in pathogenic and symbiotic conditions. Mol. Plant Microbe Interact. 21, 781-790. doi: 10.1094/MPMI-21-6-0781

Fukudome, M., Calvo-Begueria, L., Kado, T., Osuki, K. I., Rubio, M. C., Murakami, E. I., et al. (2016). Hemoglobin LjGlb1-1 is involved in nodulation and regulates the level of nitric oxide in the Lotus japonicus-Mesorhizobium loti symbiosis. J. Exp. Bot. 67, 5275-5283. doi: 10.1093/jxb/erw290

Fukudome, M., Watanabe, E., Osuki, K.-I., Imaizumi, R., Aoki, T., Becana, M., et al. (2018). Stably transformed Lotus japonicus plants overexpressing phytoglobin LjGlb1-1 show decreased nitric oxide levels in roots and nodules as well as delayed nodule senescence. Plant Cell Physiol. 60, 816-825. doi: 10.1093/pcp/ pcy245

Gage, D. J. (2004). Infection and invasion of roots by symbiotic, nitrogen-fixing rhizobia during nodulation of temperate legumes. Microbiol. Mol. Biol. Rev. 68, 280-300. doi: 10.1128/mmbr.68.2.280-300.2004

Garrocho-Villegas, V., and Arredondo-Peter, R. (2008). Molecular cloning and characterization of a moss (Ceratodon purpureus) nonsymbiotic hemoglobin provides insight into the early evolution of plant nonsymbiotic hemoglobins. Mol. Biol. Evol. 25, 1482-1487. doi: 10.1093/molbev/msn096

Geurts, R., and Bisseling, T. (2002). Rhizobium nod factor perception and signalling. Plant Cell 14, s239-s249. doi: 10.1105/tpc.002451

Gibbs, D. J., Conde, J. V., Berckhan, S., Prasad, G., Mendiondo, G. M., and Holdsworth, M. J. (2015). Group VII ethylene response factors coordinate oxygen and nitric oxide signal transduction and stress responses in plants. Plant Physiol. 169, 23-31. doi: 10.1104/pp.15.00338

Gibbs, D. J., MdIsa, N., Movahedi, M., Lozano-Juste, J., Mendiondo, G. M., Berckhan, S., et al. (2014). Nitric oxide sensing in plants is mediated by proteolytic control of group VII ERF transcription factors. Mol. Cell 53, 369379. doi: 10.1016/j.molcel.2013.12.020 
Gonzalez-Rizzo, S., Crespi, M., and Frugier, F. (2006). The Medicago truncatula CRE1 cytokinin receptor regulates lateral root development and early symbiotic interaction with Sinorhizobium meliloti. Plant Cell 18, 2680-2693. doi: 10.1105/ tpc. 106.043778

Guan, C., Wang, X., Feng, J., Hong, S., Liang, Y., Ren, B., et al. (2014). Cytokinin antagonizes abscisic acid-mediated inhibition of cotyledon greening by promoting the degradation of abscisic acid insensitive 5 protein in Arabidopsis. Plant Physiol. 164, 1515-1526. doi: 10.1104/pp.113.234740

Günther, C., Schlereth, A., Udvardi, M., and Ott, T. (2007). Metabolism of reactive oxygen species is attenuated in leghemoglobin-deficient nodules of Lotus japonicus. Mol. Plant Microbe Interact. 20, 1596-1603.

Gupta, K. J., Hebelstrup, K. H., Mur, L. A. J., and Igamberdiev, A. U. (2011a). Plant hemoglobins: important players at the crossroads between oxygen and nitric oxide. FEBS Lett. 585, 3843-3849. doi: 10.1016/j.febslet.2011.10.036

Gupta, K. J., and Igamberdiev, A. U. (2011). The anoxic plant mitochondrion as a nitrite: NO reductase. Mitochondrion 11, 537-543. doi: 10.1016/j.mito.2011. 03.005

Gupta, K. J., Igamberdiev, A. U., Manjunatha, G., Segu, S., Moran, J. F., Neelawarne, B., et al. (2011b). The emerging roles of nitric oxide (NO) in plant mitochondria. Plant Sci. 181, 520-526. doi: 10.1016/j.plantsci.2011.03.018

Heiniger, E. K., Oda, Y., Samanta, S. K., and Harwood, C. S. (2012). How posttranslational modification of nitrogenase is circumvented in Rhodopseudomonas palustris strains that produce hydrogen gas constitutively. Appl. Environ. Microbiol. 7, 1023-1032. doi: 10.1128/AEM.07254-11

Herold, S., and Puppo, A. (2005). Oxyleghemoglobin scavenges nitrogen monoxide and peroxynitrite: a possible role in functioning nodules? J. Biol. Inorg. Chem. 10, 935-945.

Hichri, I., Boscari, A., Castella, C., Rovere, M., Puppo, A., and Brouquisse, R. (2015). Nitric oxide: a multifaceted regulator of the nitrogen-fixing symbiosis. J. Exp. Bot. 66, 2877-2887. doi: 10.1093/jxb/erv051

Hill, R., Hargrove, M., and Arredondo-Peter, R. (2016). Phytoglobin: a novel nomenclature for plant globins accepted by the globin community at the 2014 XVIII conference on Oxygen-Binding and Sensing Proteins. F1000Res. 5:212. doi: 10.12688/f1000research.8133.1

Hill, R. D. (2012). Non-symbiotic haemoglobins-What's happening beyond nitric oxide scavenging? AoB Plants 2012:pls004. doi: 10.1093/aobpla/pls004

Hirsch, A. M. (1992). Developmental biology of legume nodulation. New Phytol. 122, 211-237. doi: 10.1111/j.1469-8137.1992.tb04227.x

Horchani, F., Prevot, M., Boscari, A., Evangelisti, E., Meilhoc, E., Bruand, C., et al. (2010). Both Plant and Bacterial Nitrate Reductases Contribute to Nitric Oxide Production in Medicago truncatula Nitrogen-Fixing Nodules. Plant Physiol. 155, 1023-1036. doi: 10.1104/pp.110.166140

Huang, X., Stettmaier, K., Michel, C., Hutzler, P., Mueller, M. J., and Durner, J. (2004). Nitric oxide is induced by wounding and influences jasmonic acid signaling in Arabidopsis thaliana. Planta 218, 938-946.

Huergo, L. F., Merrick, M., Monteiro, R. A., Chubatsu, L. S., Steffens, M. B. R., Pedrosa, F. O., et al. (2009). In vitro interactions between the PII proteins and the nitrogenase regulatory enzymes dinitrogenase reductase ADP-ribosyltransferase (DraT) and dinitrogenase reductase-activating glycohydrolase (DraG) in Azospirillum brasilense. J. Biol. Chem. 284, 6674-6682. doi: 10.1074/jbc.M807378200

Hunt, P. W., Watts, R. A., Trevaskis, B., Llewelyn, D. J., Burnell, J., Dennis, E. S., et al. (2001). Expression and evolution of functionally distinct haemoglobin genes in plants. Plant Mol. Biol. 47, 677-692.

Igamberdiev, A. U., Bykova, N. V., Shah, J. K., and Hill, R. D. (2010). Anoxic nitric oxide cycling in plants: participating reactions and possible mechanisms. Physiol. Plant. 138, 393-404. doi: 10.1111/j.1399-3054.2009.01314.x

Igamberdiev, A. U., and Hill, R. D. (2004). Nitrate, NO and haemoglobin in plant adaptation to hypoxia: an alternative to classic fermentation pathways. J. Exp. Bot. 55, 2473-2482. doi: 10.1093/jxb/erh272

Jaszek, M., Janczarek, M., Kuczyński, K., Piersiak, T., and Grzywnowicz, K. (2014). The response of the Rhizobium leguminosarum bv. trifolii wild-type and exopolysaccharide-deficient mutants to oxidative stress. Plant Soil 376, 75-94.

Kato, K., Kanahama, K., and Kanayama, Y. (2010). Involvement of nitric oxide in the inhibition of nitrogenase activity by nitrate in Lotus root nodules. J. Plant Physiol. 167, 238-241. doi: 10.1016/j.jplph.2009.08.006
Klessig, D. F., Durner, J., Noad, R., Navarre, D. A., Wendehenne, D., Kumar, D., et al. (2000). Nitric oxide and salicylic acid signaling in plant defense. Proc. Natl. Acad. Sci. U.S.A. 97, 8849-8855. doi: 10.1073/pnas.97.16.8849

Kovacs, I., and Lindermayr, C. (2013). Nitric oxide-based protein modification: formation and site-specificity of protein S-nitrosylation. Front. Plant Sci. 4:137. doi: 10.3389/fpls.2013.00137

Laranjo, M., Alexandre, A., and Oliveira, S. (2014). Legume growth-promoting rhizobia: an overview on the Mesorhizobium genus. Microbiol. Res. 169, 2-17. doi: 10.1016/j.micres.2013.09.012

Lehotai, N., Lyubenova, L., Schröder, P., Feigl, G., Ördög, A., Szilágyi, K., et al. (2016). Nitro-oxidative stress contributes to selenite toxicity in pea (Pisum sativum L). Plant Soil 400, 107-122. doi: 10.1007/s11104-015-2716-x

León, J., and Costa-Broseta, Á. (2020). Present knowledge and controversies, deficiencies, and misconceptions on nitric oxide synthesis, sensing, and signaling in plants. Plant Cell Environ. 43, 1-15. doi: 10.1111/pce.13617

Lindström, K., Murwira, M., Willems, A., and Altier, N. (2010). The biodiversity of beneficial microbe-host mutualism: the case of rhizobia. Res. Microbiol. 161, 453-463. doi: 10.1016/j.resmic.2010.05.005

Lozano-Juste, J., and Leon, J. (2011). Nitric oxide regulates DELLA content and PIF expression to promote photomorphogenesis in Arabidopsis. Plant Physiol. 156, 1410-1423. doi: 10.1104/pp.111.177741

Maiti, D., Sarkar, T. S., and Ghosh, S. (2012). Detection of S-nitrosothiol and nitrosylated proteins in Arachis hypogaea functional nodule: response of the nitrogen fixing symbiont. PLoS One 7:e45526. doi: 10.1371/journal.pone. 0045526

Marhavý, P., Duclercq, J., Weller, B., Feraru, E., Bielach, A., Offringa, R., et al. (2014). Cytokinin controls polarity of PIN1-dependent Auxin transport during lateral root organogenesis. Curr. Biol. 24, 1031-3037. doi: 10.1016/j.cub.2014. 04.002

Marino, D., Andrio, E., Danchin, E. G. J., Oger, E., Gucciardo, S., Lambert, A., et al. (2011). A Medicago truncatula NADPH oxidase is involved in symbiotic nodule functioning. New Phytol. 189, 580-592. doi: 10.1111/j.1469-8137.2010.03509.x

Marino, D., Pucciariello, C., Puppo, A., and Frendo, P. (2009). The redox state, a referee of the legume-rhizobia symbiotic game. Adv. Bot. Res. 52, 115-151. doi: 10.1016/S0065-2296(10)52005-6

Masson-Boivin, C., Giraud, E., Perret, X., and Batut, J. (2009). Establishing nitrogen-fixing symbiosis with legumes: how many rhizobium recipes? Trends Microbiol. 17, 458-466. doi: 10.1016/j.tim.2009.07.004

Meilhoc, E., Cam, Y., Skapski, A., and Bruand, C. (2010). The response to nitric oxide of the nitrogen-fixing symbiont Sinorhizobium meliloti. Mol. Plant Microbe Interact. 23, 748-759. doi: 10.1094/MPMI-23-6-0748

Meitha, K., Agudelo-Romero, P., Signorelli, S., Gibbs, D. J., Considine, J. A., Foyer, C. H., et al. (2018). Developmental control of hypoxia during bud burst in grapevine. Plant Cell Environ. 41, 1154-1170. doi: 10.1111/pce.13141

Melo, P. M., Silva, L. S., Ribeiro, I., Seabra, A. R., and Carvalho, H. G. (2011) Glutamine synthetase is a molecular target of nitric oxide in root nodules of Medicago truncatula and is regulated by tyrosine nitration. Plant Physiol. 157, 1505-1517. doi: 10.1104/pp.111.186056

Michalski, W. P., and Nicholas, D. J. D. (1987). Inhibition of nitrogenase by nitrite and nitric oxide in Rhodopseudomonas sphaeroides f. sp. denitrificans. Arch. Microbiol. 147, 304-308. doi: 10.1007/BF00463493

Millar, A. H., Day, D. A., and Bergersen, F. J. (1995). Microaerobic respiration and oxidative phosphorylation by soybean nodule mitochondria: implications for nitrogen fixation. Plant Cell Environ. 18, 715-726. doi: 10.1111/j.1365-3040. 1995.tb00574.x

Millar, A. H., Finnegan, P. M., Whelan, J., Drevon, J. J., and Day, D. A. (1997). Expression and kinetics of the mitochondrial alternative oxidase in nitrogen-fixing nodules of soybean roots. Plant Cell Environ. 20, 1273-1282. doi: 10.1046/j.1365-3040.1997.d01-25.x

Millar, H. A., and Day, D. A. (1996). Nitric oxide inhibits the cytochrome oxidase but not the alternative oxidase of plant mitochondria. FEBS Lett. 398, 155-158.

Miwa, H., Sun, J., Oldroyd, G. E. D., and Downie, J. A. (2006). Analysis of Nod-factor-induced calcium signaling in root hairs of symbiotically defective mutants of Lotus japonicus. Mol. Plant Microbe Interact. 19, 914-923.

Monza, J., Irisarri, P., Díaz, P., Delgado, M. J., Mesa, S., and Bedmar, E. J. (2006). Denitrification ability of rhizobial strains isolated from Lotus sp. Antonie Van Leeuwenhoek 89, 479-484. 
Moreau, S., Davies, M. J., and Puppo, A. (1995). Reaction of ferric leghemoglobin with $\mathrm{H}_{2} \mathrm{O}_{2}$ : formation of heme-protein cross-links and dimeric species. Biochim. Biophys. Acta 1251, 17-22. doi: 10.1016/0167-4838(95)00087-B

Murakami, Y., Miwa, H., Imaizumi-Anraku, H., Kouchi, H., Downie, J. A., Kawaguchi, M., et al. (2007). Positional cloning identifies Lotus japonicus NSP2, a putative transcription factor of the GRAS family, required for NIN and ENOD40 gene expression in nodule initiation. DNA Res. 13, 255-265. doi: 10.1093/dnares/ds1017

Nagata, M., Murakami, E., Shimoda, Y., Shimoda-Sasakura, F., Kucho, K., Suzuki, A., et al. (2008). Expression of a Class 1 hemoglobin gene and production of nitric oxide in response to symbiotic and pathogenic bacteria in Lotus japonicus. Mol. Plant Microbe Interact. 21, 1175-1183.

Nagata, M., and Suzuki, A. (2014). "Effects of phytohormones on nodulation and nitrogen fixation in leguminous plants," in Advances in Biology and Ecology of Nitrogen Fixation, ed. T. Ohyama (Rijeka: InTech), 111-128. doi: 10.5772/57267

Navascues, J., Perez-Rontome, C., Gay, M., Marcos, M., Yang, F., Walker, F. A., et al. (2012). Leghemoglobin green derivatives with nitrated hemes evidence production of highly reactive nitrogen species during aging of legume nodules. Proc. Natl. Acad. Sci. U.S.A. 109, 2660-2665. doi: 10.1073/pnas.1116559109

Oldroyd, G. E. D., and Dixon, R. (2014). Biotechnological solutions to the nitrogen problem. Curr. Opin. Biotechnol. 26, 19-54. doi: 10.1016/j.copbio.2013.08.006

Penmetsa, R. V., Frugoli, J. A., Smith, L. S., Long, S. R., and Cook, D. R. (2003). Dual genetic pathways controlling nodule number in Medicago truncatula. Plant Physiol. 131, 998-1008. doi: 10.1104/pp.015677

Perazzolli, M., Dominici, P., Romero-Puertas, M. C., Zago, E., Zeier, J., Sonoda, M., et al. (2004). Arabidopsis nonsymbiotic hemoglobin AHb1 modulates nitric oxide bioactivity. Plant Cell 16, 2785-2794. doi: 10.1105/tpc.104.025379

Phillips, D. A. (1971). Abscisic acid inhibition of root nodule initiation in Pisum sativum. Planta 100, 181-190. doi: 10.1007/BF00387034

Pii, Y., Crimi, M., Cremonese, G., Spena, A., and Pandolfini, T. (2007). Auxin and nitric oxide control indeterminate nodule formation. BMC Plant Biol. 7:21. doi: 10.1186/1471-2229-7-21

Planchet, E., Gupta, K. J., Sonoda, M., and Kaiser, W. M. (2005). Nitric oxide emission from tobacco leaves and cell suspensions: rate limiting factors and evidence for the involvement of mitochondrial electron transport. Plant J. 41, 732-743. doi: 10.1111/j.1365-313X.2005.02335.x

Plet, J., Wasson, A., Ariel, F., Le Signor, C., Baker, D., Mathesius, U., et al. (2011). MtCRE1-dependent cytokinin signaling integrates bacterial and plant cues to coordinate symbiotic nodule organogenesis in Medicago truncatula. Plant J. 65, 622-633. doi: 10.1111/j.1365-313X.2010.04447.x

Pope, M. R., Murrell, S. A., and Ludden, P. W. (1985). Covalent modification of the iron protein of nitrogenase from Rhodospirillum rubrum by adenosine diphosphoribosylation of a specific arginine residue. Proc. Natl. Acad. Sci. U.S.A. 82, 3173-3177. doi: 10.1073/pnas.82.10.3173

Puppo, A., Dimitrijevic, L., and Rigaud, J. (1982). Possible involvement of nodule superoxide dismutase and catalase in leghemoglobin protection. Planta 50, 374-379.

Puppo, A., Rigaud, J., and Job, D. (1981). Role of superoxide anion in leghemoglobin autoxidation. Plant Sci. Lett. 22, 353-360. doi: 10.1016/03044211(81)90081-X

Puppo, A., Pauly, N., Boscari, A., Mandon, K., and Brouquisse, R. (2013). Hydrogen Peroxide and Nitric Oxide: Key Regulators of the Legume-Rhizobium and Mycorrhizal Symbioses. Antioxid. Redox Signal. 18, 2202-2019. doi: 10.1089/ ars.2012.5136.

Ramu, S. K.,Peng, H.-M. and Cook, D. R. (2002). Nod factor induction of reactive oxygen species production is correlated with expression of the early nodulin gene rip1 in Medicago truncatula. Mol. Plant Microbe Interact. 15, 522-528. doi: 10.1094/mpmi.2002.15.6.522

Roy, S., Liu, W., Nandety, R. S., Crook, A., Mysore, K. S., Pislariu, C. I., et al. (2020). Celebrating 20 years of genetic discoveries in legume nodulation and symbiotic nitrogen fixation. Plant Cell 132, 15-41. doi: 10.1105/tpc.19.00279

Rümer, S., Gupta, K. J., and Kaiser, W. M. (2009). Plant cells oxidize hydroxylamines to NO. J. Exp. Bot. 4, 853-855. doi: 10.1093/jxb/ erp077

Sainz, M., Calvo-Begueria, L., Pérez-Rontomé, C., Wienkoop, S., Abián, J., Staudinger, C., et al. (2015). Leghemoglobin is nitrated in functional legume nodules in a tyrosine residue within the heme cavity by a nitrite/peroxidedependent mechanism. Plant J. 81, 723-735. doi: 10.1111/tpj.12762
Sainz, M., Pérez-Rontomé, C., Ramos, J., Mulet, J. M., James, E. K., Bhattacharjee, U., et al. (2013). Plant hemoglobins may be maintained in functional form by reduced flavins in the nuclei, and confer differential tolerance to nitro-oxidative stress. Plant J. 76, 875-887. doi: 10.1111/tpj.12340

Sánchez, C., Gates, A. J., Meakin, G. E., Uchiumi, T., Girard, L., Richardson, D. J., et al. (2010). Production of nitric oxide and nitrosylleghemoglobin complexes in soybean nodules in response to flooding. Mol. Plant Microbe Interact. 23, 702-711.

Sanz, L., Fernandez-Marcos, M., Modrego, A., Lewis, D. R., Muday, G. K., Pollmann, S., et al. (2014). Nitric oxide plays a role in stem cell niche homeostasis through its interaction with auxin. Plant Physiol. 166, 1972-1984. doi: 10.1104/pp.114.247445

Sanz-Luque, E., Ocańa-Calahorro, F., De Montaigu, A., Chamizo-Ampudia, A., Llamas, Á., Galván, A., et al. (2015). THB1, a truncated hemoglobin, modulates nitric oxide levels and nitrate reductase activity. Plant J. 81, 467-479. doi: $10.1111 /$ tpj. 12744

Schauser, L., Roussis, A., Stiller, J., and Stougaard, J. (1999). A plant regulator controlling development of symbiotic root nodules. Nature 402, 191-195. doi: $10.1038 / 46058$

Serraj, R., Sinclair, T. R., and Purcell, L. C. (1999). Symbiotic N2 fixation response to drought. J. Exp. Bot. 50, 143-155. doi: 10.1093/jxb/50.331.143

Shimoda, Y., Nagata, M., Suzuki, A., Abe, M., Sato, S., Kato, T., et al. (2005). Symbiotic rhizobium and nitric oxide induce gene expression of non-symbiotic hemoglobin in Lotus japonicus. Plant Cell Physiol. 46, 99-107. doi: 10.1093/pci/ pci001

Shimoda, Y., Shimoda-Sasakura, F., Kucho, K. I., Kanamori, N., Nagata, M., Suzuki, A., et al. (2009). Overexpression of class 1 plant hemoglobin genes enhances symbiotic nitrogen fixation activity between Mesorhizobium loti and Lotus japonicus. Plant J. 57, 254-263. doi: 10.1111/j.1365-313X.2008.03689.x

Sievers, G., Ronnberg, M., and Rönnberg, M. (1978). Study of the pseudoperoxidatic activity of soybean leghemoglobin and sperm whale myoglobin. BBA Protein Struct. 533, 293-301.

Signorelli, S., and Considine, M. J. (2018). Nitric oxide enables germination by a four-pronged attack on ABA-induced seed dormancy. Front. Plant Sci. 9:296. doi: 10.3389/fpls.2018.00296

Signorelli, S., Corpas, F. J., Borsani, O., Barroso, J. B., and Monza, J. (2013). Water stress induces a differential and spatially distributed nitro-oxidative stress response in roots and leaves of Lotus japonicus. Plant Sci. 20, 137-146. doi: 10.1016/j.plantsci.2012.12.004

Signorelli, S., Corpas, F. J., Rodríguez-Ruiz, M., Valderrama, R., Barroso, J. B., Borsani, O., et al. (2019). Drought stress triggers the accumulation of NO and SNOs in cortical cells of Lotus japonicus L. roots and the nitration of proteins with relevant metabolic function. Environ. Exp. Bot. 161, 228-241. doi: 10.1016/j.envexpbot.2018.08.007

Signorelli, S., Möller, M. N., Coitińo, E. L., and Denicola, A. (2011). Nitrogen dioxide solubility and permeation in lipid membranes. Arch. Biochem. Biophys. 512, 190-196. doi: 10.1016/j.abb.2011.06.003

Sinclair, T. R., and Serraj, R. (1995). Legume nitrogen fixation and drought. Nature 378:344. doi: 10.1038/378344a0

Skubacz, A., Daszkowska-Golec, A., and Szarejko, I. (2016). The role and regulation of ABI5 (ABA-Insensitive 5) in plant development, abiotic stress responses and phytohormone crosstalk. Front. Plant Sci. 7:1884. doi: 10.3389/fpls.2016.01884

Smagghe, B. J., Hoy, J. A., Percifield, R., Kundu, S., Hargrove, M. S., Sarath, G., et al. (2009). Correlations between oxygen affinity and sequence classifications of plant hemoglobins. Biopolymers 91, 1083-1096. doi: 10.1002/bip.21256

Stacey, G., McAlvin, C. B., Kim, S. Y., Olivares, J., and Soto, M. J. (2006). Effects of endogenous salicylic acid on nodulation in the model legumes Lotus japonicus and Medicago truncatula. Plant Physiol. 141, 1473-1481. doi: 10.1104/pp.106. 080986

Stöhr, C., Strube, F., Marx, G., Ullrich, W. R., and Rockel, P. (2001). A plasma membrane-bound enzyme of tobacco roots catalyses the formation of nitric oxide from nitrite. Planta 212, 835-841. doi: 10.1007/s004250000447

Stoimenova, M., Igamberdiev, A. U., Gupta, K. J., and Hill, R. D. (2007). Nitritedriven anaerobic ATP synthesis in barley and rice root mitochondria. Planta $226,465-474$.

Sulieman, S., and Tran, L. S. P. (2015). "Introduction," in Legume nitrogen fixation in a changing environment: Achievements and challenges, eds S. Sulieman and L. S. P. Tran (Cham: Springer International Publishing), 1-3. 
Suzaki, T., Yano, K., Ito, M., Umehara, Y., Suganuma, N., and Kawaguchi, M. (2012). Positive and negative regulation of cortical cell division during root nodule development in Lotus japonicus is accompanied by auxin response. Development 139, 3997-4006. doi: 10.1242/dev.084079

Suzuki, A., Akune, M., Kogiso, M., Imagama, Y., Osuki, K. I., Uchiumi, T., et al. (2004). Control of nodule number by the phytohormone abscisic acid in the roots of two leguminous species. Plant Cell Physiol. 45, 914-922. doi: 10.1093/ pcp/pch107

Tarkowski, Ł. P., Signorelli, S., and Höfte, M. (2020). GABA and related amino acids in plant immune responses: emerging mechanisms of action. Plant Cell Environ. doi: 10.1111/pce.13734 [Epub ahead of print].

Tartaglia, C., Gutierrez, P., Sabatini, O., Irisarri, P., Signorelli, S., Rebuffo, M., et al. (2019). "Caracterizacioin de rizobios que nodulan Trifolium polymorphum," in Cepas Nativas Para Desarrollar un Inoculante Rizobiano Competitivo y Eficiente en Treibol Blanco, ed. Unidad de Comunicación y Transferencia de Tecnología de INIA. (Montevideo: INIA), 33-45.

Tominaga, A., Nagata, M., Futsuki, K., Abe, H., Uchiumi, T., Abe, M., et al. (2009). Enhanced nodulation and nitrogen fixation in the abscisic acid low-sensitive mutant enhanced nitrogen fixation 1 of Lotus japonicus. Plant Physiol. 151, 1965-1976. doi: 10.1104/pp.109.142638

Tominaga, A., Nagata, M., Futsuki, K., Abe, H., Uchiumi, T., Abe, M., et al. (2010). Effect of abscisic acid on symbiotic nitrogen fixation activity in the root nodules of Lotus japonicus. Plant Signal. Behav. 5, 440-443. doi: 10.4161/psb.5.4. 10849

Trinchant, J. C., and Rigaud, J. (1982). Nitrite and nitric oxide as inhibitors of nitrogenase from soybean bacteroids. Appl. Environ. Microbiol. 44, 1385-1388.

Tun, N. N., Santa-Catarina, C., Begum, T., Silveira, V., Handro, W., Segal Floh, E. I., et al. (2006). Polyamines induce rapid biosynthesis of nitric oxide (NO) in Arabidopsis thaliana seedlings. Plant Cell Physiol. 47, 346-354. doi: 10.1093/ pcp/pci252

Vieweg, M. F., Hohnjec, N., and Küster, H. (2005). Two genes encoding different truncated hemoglobins are regulated during root nodule and arbuscular mycorrhiza symbioses of Medicago truncatula. Planta 220, 757-766.

Vigeolas, H., Hühn, D., and Geigenberger, P. (2011). Nonsymbiotic hemoglobin-2 leads to an elevated energy state and to a combined increase in polyunsaturated fatty acids and total oil content when overexpressed in developing seeds of transgenic arabidopsis plants. Plant Physiol. 155, 1435-1444. doi: 10.1104/pp. 110.166462
Wang, P., Du, Y., Hou, Y.-J., Zhao, Y., Hsu, C.-C., Yuan, F., et al. (2015a). Nitric oxide negatively regulates abscisic acid signaling in guard cells by S-nitrosylation of OST1. Proc. Natl. Acad. Sci. U.S.A. 112, 613-618. doi: $10.1073 /$ pnas. 1423481112

Wang, P., Zhu, J. K., and Lang, Z. (2015b). Nitric oxide suppresses the inhibitory effect of abscisic acid on seed germination by S-nitrosylation of SnRK2 proteins. Plant Signal. Behav. 10:e1031939. doi: 10.1080/15592324.2015.1031939

Watts, R. A., Hunt, P. W., Hvitved, A. N., Hargrove, M. S., Peacock, W. J., and Dennis, E. S. (2001). A hemoglobin from plants homologous to truncated hemoglobins of microorganisms. Proc. Natl. Acad. Sci. U.S.A. 98, 10119-10124.

Wittenberg, J. B., Bolognesi, M., Wittenberg, B., and Guertin, M. (2002). Truncated hemoglobins: a new family of hemoglobins widely distributed in bacteria, unicellular eukaryotes, and plants. J. Biol. Chem. 277, 871-874. doi: 10.1074/ jbc.R100058200

Zdyb, A., Demchenko, K., Heumann, J., Mrosk, C., Grzeganek, P., Göbel, C., et al. (2011). Jasmonate biosynthesis in legume and actinorhizal nodules. New Phytol. 189, 568-579. doi: 10.1111/j.1469-8137.2010.03504.x

Zhu, L., Liu, X., Liu, X., Jeannotte, R., Reese, J. C., Harris, M., et al. (2005). Two genes encoding different truncated hemoglobins are regulated during root nodule and arbuscular mycorrhiza symbioses of Medicago truncatula. Planta 220, 757-766.

Conflict of Interest: The authors declare that the research was conducted in the absence of any commercial or financial relationships that could be construed as a potential conflict of interest.

The handling editor declared a past co-authorship with several of the authors SS and JM.

Copyright (c) 2020 Signorelli, Sainz, Tabares-da Rosa and Monza. This is an openaccess article distributed under the terms of the Creative Commons Attribution License (CC BY). The use, distribution or reproduction in other forums is permitted, provided the original author(s) and the copyright owner(s) are credited and that the original publication in this journal is cited, in accordance with accepted academic practice. No use, distribution or reproduction is permitted which does not comply with these terms. 